\title{
At the poles across kingdoms: phosphoinositides and polar tip growth
}

\author{
Till Ischebeck • Stephan Seiler • Ingo Heilmann
}

Received: 17 November 2009 / Accepted: 20 November 2009/Published online: 20 December 2009

(C) The Author(s) 2009. This article is published with open access at Springerlink.com

\begin{abstract}
Phosphoinositides (PIs) are minor, but essential phospholipid constituents of eukaryotic membranes, and are involved in the regulation of various physiological processes. Recent genetic and cell biological advances indicate that PIs play important roles in the control of polar tip growth in plant cells. In root hairs and pollen tubes, PIs control directional membrane trafficking required for the delivery of cell wall material and membrane area to the growing tip. So far, the exact mechanisms by which PIs control polarity and tip growth are unresolved. However, data gained from the analysis of plant, fungal and animal systems implicate PIs in the control of cytoskeletal dynamics, ion channel activity as well as vesicle trafficking. The present review aims at giving an overview of PI roles in eukaryotic cells with a special focus on functions pertaining to the control of cell polarity. Comparative screening of plant and fungal genomes suggests diversification of the PI system with increasing organismic complexity. The evolutionary conservation of the PI system among eukaryotic cells suggests a role for PIs in tip growing cells in models where PIs so far have not been a focus of attention, such as fungal hyphae.
\end{abstract}

\footnotetext{
T. Ischebeck $\cdot$ I. Heilmann $(\bowtie)$

Department of Plant Biochemistry,

Georg-August-University Göttingen,

Justus-von-Liebig-Weg 11,

37077 Göttingen, Germany

e-mail: iheilma@uni-goettingen.de

S. Seiler

Department of Microbiology and Genetics; and DFG Research

Center Molecular Physiology of the Brain (CMPB),

Georg-August-University Göttingen,

Grisebachstraße 8,

37077 Göttingen, Germany
}

Keywords Polar tip growth · Phosphoinositides · Arabidopsis thaliana $\cdot$ Neurospora crassa $\cdot$ Physcomitrella patens $\cdot$ Comparative biology

$\begin{array}{ll}\text { Abbreviations } & \\ \text { ABP } & \text { Actin-binding protein } \\ \text { DAG } & \text { Diacylglycerol } \\ \text { GAP } & \text { GTPase-activating protein } \\ \text { GDI } & \text { GDP-dissociation inhibitor } \\ \text { GEF } & \text { Guanine nucleotide exchange factor } \\ \text { PI } & \text { Phosphoinositide } \\ \text { PIS } & \text { PI-synthase } \\ \text { PME } & \text { Pectin methyl esterase } \\ \text { PtdIns } & \text { Phosphatidylinositol } \\ \text { PtdIns3P } & \text { PtdIns-3-phosphate } \\ \text { PtdIns4P } & \text { PtdIns-4-phosphate } \\ \text { PtdIns5P } & \text { PtdIns-5-phosphate } \\ \text { PtdIns(3,4) } \mathrm{P}_{2} & \text { PtdIns-3,4-bisphosphate } \\ \text { PtdIns(3,5)P } 2 & \text { PtdIns-3,5-bisphosphate } \\ \text { PtdIns(4,5)P } 2 & \text { PtdIns-4,5-bisphosphate }\end{array}$

\section{Introduction}

Cell polarity is a prerequisite for the establishment of particular cell shapes, for directional cell movement, and consequently for cellular differentiation during organ development. Therefore, much effort has been invested into understanding the physiological processes leading to the establishment of an axis of cell polarity and the ensuing asymmetric cell divisions that underlie the development of complex multicellular organisms. A number of model systems that allow the analysis of cell polarity on the level of single cells have been established that represent different 
organismal kingdoms, including animal, fungal, and plant cells. Extreme examples of polar cell growth include neurites, fungal hyphae, moss protonemata, and root hairs and pollen tubes of higher plants. Despite the distant phylogenetic relationships between these organisms, it is becoming increasingly apparent that the molecular mechanisms for establishing and maintaining cell polarity have been conserved in evolution and can be dated back prior to the separation of the common ancestors of animal, fungal, and plant cells. While each phylum has developed its particular adaptations to specific cellular requirements, the molecular building blocks have remained recognizable over time. A wide variety of studies has identified numerous proteins as key players required for cell polarity and directional tip growth. However, proteins only constitute part of the machinery for polar growth, and it is important to recognize the roles of other players, such as those of regulatory phospholipids, which are the focus of this review. In recent years, the involvement of phosphoinositides (PIs) in the control of polar tip growth of pollen tubes and root hairs has been studied in some depth, and the information gained from the scrutiny of these plant models may aid the understanding of polar tip growth in other eukaryotic systems.

\section{Regulatory phospholipids: the PI system}

Phospholipids account for the majority of lipids constituting most prokaryotic and eukaryotic membranes, with the exception of plant thylakoids. While some phospholipids, such as phosphatidylethanolamine or phosphatidylcholine are highly abundant and have primarily structural roles, others such as PIs occur to a much smaller extent. Phosphatidylinositol (PtdIns), the precursor of all PIs, is generated by the condensation of cytidine-diphosphodiacylglycerol (CDP-
DAG) and D-myo-inositol catalyzed by PtdIns synthases (PIS) (Takenawa and Egawa 1977; Fischl and Carman 1983; Parries and Hokin-Neaverson 1984; Justin et al. 1995; Jackson et al. 2000). The first gene encoding a PIS was identified in yeast (Nikawa et al. 1987), and later the Arabidopsis thaliana homolog, PIS1, was described (Collin et al. 1999; Justin et al. 2002). A. thaliana also contains a second isoenzyme, PIS2, with high similarity to PIS1 (Löfke et al. 2008). Both PISs from A. thaliana are localized in the ER (Löfke et al. 2008), with their catalytic centers likely oriented to the cytosolic face of the ER membrane. PIs, which derive from PtdIns by phosphorylation of the inositol headgroup, exhibit pronounced asymmetry between membrane leaflets with the vast majority present in the cytosolic leaflet (Gascard et al. 1991; Vidugiriene and Menon 1993, 1994).

The inositol ring of PtdIns can be phosphorylated at the D-3, D-4, and D-5 position by specific lipid kinases that, so far, have only been found in eukaryotes (Anderson et al. 1999; Drobak et al. 1999). The various phosphorylations can be carried out in consecutive steps, giving rise to a total of six structurally related PIs (Fig. 1). For instance, phosphatidylinositol-4-phosphate (PtdIns4P) can be formed from PtdIns by PI 4-kinases, or phosphatidylinositol-4,5bisphosphate $\left(\operatorname{PtdIns}(4,5) \mathrm{P}_{2}\right)$ from PtdIns4P by PI4P 5kinases. A seventh PI, PtdIns $(3,4,5) \mathrm{P}_{3}$, has so far only been reported in animal cells. Phosphoinositide kinases, such as PI 4-kinases or PI4P 5-kinases, can each be represented by different subfamilies of enzymes, that can have non-redundant functionality. For instance, in the yeast Saccharomyces cerevisiae three PI 4-kinases with non-redundant functions exist (Table 1) which represent two distinct enzyme classes (Shelton et al. 2003; Demmel et al. 2008). In A. thaliana, four ubiquitously expressed homologs of the yeast enzymes Stt4p (staurosporine and temperature sensitive 4) and Pik1p
Fig. 1 Structures of phosphoinositides found in plants and fungi. PtdIns $3 P$ phosphatidylinositol-3phosphate, PtdIns $4 P$ phosphatidylinositol-4phosphate, PtdIns5P phosphatidylinositol-5phosphate, PtdIns $(3,5) P_{2}$ phosphatidylinositol-3,5bisphosphate, $\operatorname{PtdIns}(4,5) P_{2}$ phosphatidylinositol-4,5bisphosphate, $\operatorname{PtdIns}(3,4) \mathrm{P}_{2}$ phosphatidylinositol-3,4bisphosphate
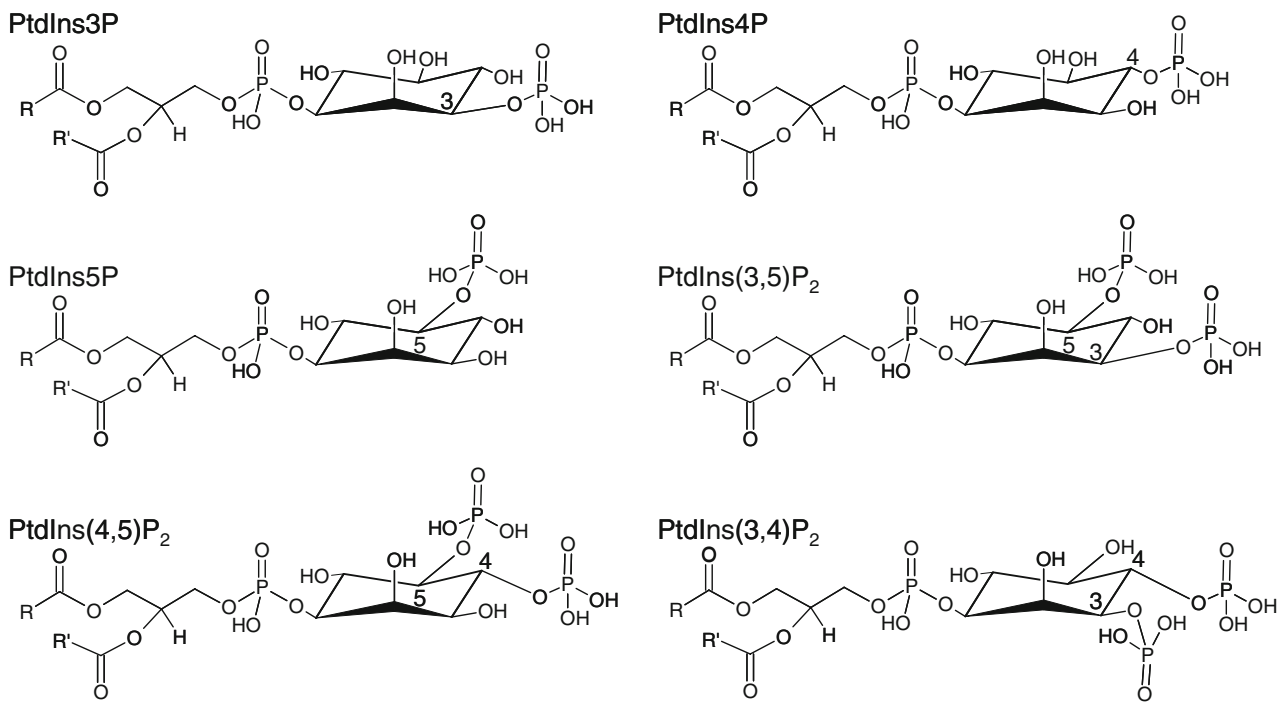
Table 1 For protein IDs refer to http://www.yeastgenome.org (S. cerevisiae), http://www.broadinstitute.org/annotation/genome/neurospora/Home. html (N. crassa), http://www.A. thaliana.org (A. thaliana) and http://genome.jgi-psf.org/Phypa1_1/Phypa1_1.home.html (P. patens)

\begin{tabular}{|c|c|c|c|c|}
\hline Enzyme & S. cerevisiae & N. $\operatorname{crass}^{\mathrm{a}}$ & P. patens ${ }^{\mathrm{b}}$ & A. thaliana $^{\mathrm{c}}$ \\
\hline \multicolumn{5}{|l|}{ PI3-kinases } \\
\hline Class III & Vps $34^{d}$ & NCU00656 ${ }^{\mathrm{d}, \mathrm{e}}(\mathrm{e}-154)$ & $182554^{\mathrm{f}}(0.0)$ & $\operatorname{AtVps} 34^{e, f}(e-147)$ \\
\hline \multicolumn{5}{|l|}{ PI4-kinases } \\
\hline \multirow[t]{8}{*}{ Type II } & $\operatorname{Lsb} 6^{\mathrm{d}}$ & NCU04355 ${ }^{\mathrm{d}}(\mathrm{e}-50)$ & $167250^{\mathrm{f}}(\mathrm{e}-155 /-169 /-166 /-97 /-102)$ & AtPI4K $\gamma 5^{\mathrm{f}}(\mathrm{e}-8)$ \\
\hline & & & $118668^{\mathrm{f}}(\mathrm{e}-152 /-157 /-153 /-99 /-101)$ & AtPI4K $\gamma 6^{\mathrm{f}}(\mathrm{e}-8)$ \\
\hline & & & & AtPI4K $\gamma 7^{\mathrm{f}}(\mathrm{e}-8)$ \\
\hline & & & & AtPI4K $\gamma 1(\mathrm{e}-7)$ \\
\hline & & & & AtPI4K $\gamma 8(\mathrm{e}-6)$ \\
\hline & & & $212283^{\mathrm{f}}(\mathrm{e}-159 /-150 /-99)$ & AtPI4K $\gamma 3^{\mathrm{f}}(\mathrm{e}-5)$ \\
\hline & & & $146744^{\mathrm{f}}(\mathrm{e}-149 /-147 /-100)$ & AtPI4K $\gamma 4^{\mathrm{f}}(\mathrm{e}-5)$ \\
\hline & & & & AtPI4K $\gamma 2(e-5)$ \\
\hline \multirow[t]{4}{*}{ Type III } & $\mathrm{Stt} 4^{\mathrm{d}}$ & NCU09367 ${ }^{\mathrm{d}, \mathrm{e}}(0.0)$ & $10058^{\mathrm{f}}$ (gene model uncertain; e-110/-110) & AtPI4K $\alpha 1^{\mathrm{e}, \mathrm{f}}(\mathrm{e}-109)$ \\
\hline & & & $213798^{\mathrm{f}}$ (gene model uncertain; e-109/-109) & AtPI4K $\alpha 2^{\mathrm{f}}(\mathrm{e}-78)$ \\
\hline & Pik $1^{d}$ & NCU10397 ${ }^{\mathrm{d}, \mathrm{e}}(\mathrm{e}-131)$ & $147576^{\mathrm{f}}(0.0 / 0.0)$ & AtPI4K $\beta 1^{\mathrm{e}, \mathrm{f}}(\mathrm{e}-60)$ \\
\hline & & & $235037^{\mathrm{f}}$ (fragment; 0.0/e-177) & AtPI4K $\beta 2^{\mathrm{e}, \mathrm{f}}(\mathrm{e}-59)$ \\
\hline \multicolumn{5}{|c|}{ PI4P5-kinases } \\
\hline \multirow[t]{9}{*}{ Group B } & $M s s 4^{\mathrm{d}}$ & NCU02295 ${ }^{\mathrm{d}, \mathrm{e}}(\mathrm{e}-110)$ & $40660^{\mathrm{f}}$ ( 0.0 for all comparisons with group A proteins) & AtPIP5K1 ${ }^{\mathrm{e}, \mathrm{f}}(\mathrm{e}-56)$ \\
\hline & & & $30361^{\mathrm{f}}(0.0$ for all comparisons with group A proteins) & AtPIP5K2 ${ }^{\mathrm{e}, \mathrm{f}}(\mathrm{e}-56)$ \\
\hline & & & & AtPIP5K3 ${ }^{\mathrm{e}, \mathrm{f}}(\mathrm{e}-56)$ \\
\hline & & & & AtPIP5K4 ${ }^{\mathrm{e}, \mathrm{f}}(\mathrm{e}-56)$ \\
\hline & & & & AtPIP5K5 $5^{\mathrm{e}, \mathrm{f}}(\mathrm{e}-54)$ \\
\hline & & & & AtPIP5K6 ${ }^{\mathrm{e}, \mathrm{f}}(\mathrm{e}-55)$ \\
\hline & & & & AtPIP5K7 ${ }^{\mathrm{e}, \mathrm{f}}(\mathrm{e}-54)$ \\
\hline & & & & AtPIP5K $8^{\mathrm{e}, \mathrm{f}}(\mathrm{e}-54)$ \\
\hline & & & & AtPIP5K9 $9^{\mathrm{e}, \mathrm{f}}(\mathrm{e}-55)$ \\
\hline \multirow[t]{2}{*}{ Group A } & / & l & / & AtPIPK10 (e-30) \\
\hline & & & & AtPIPK11 (e-29) \\
\hline \multicolumn{5}{|c|}{ PI3P5-kinases } \\
\hline & $\mathrm{Fabl}^{\mathrm{d}}$ & NCU02083 ${ }^{\mathrm{d}, \mathrm{e}}(\mathrm{e}-114)$ & $121474^{\mathrm{f}}$ ( 0.0 for all comparisons $)$ & AtFabla $a^{e, f}(e-67)$ \\
\hline & & & $210788^{\mathrm{f}}$ ( 0.0 for all comparisons $)$ & $\operatorname{AtFab}_{1} \mathrm{~b}^{\mathrm{e}, \mathrm{f}}(\mathrm{e}-68)$ \\
\hline & & & $40158^{\mathrm{f}}$ (fragment; e-126/-113/-106/-82) & AtFab1 $c^{e, f}(e-68)$ \\
\hline & & & $121423^{\mathrm{f}}$ (fragment; e-95/-92/-89/-70) & $\operatorname{AtFab1d}^{\mathrm{f}}(\mathrm{e}-55)$ \\
\hline \multicolumn{5}{|c|}{ PI-phospholipase C } \\
\hline \multirow[t]{9}{*}{ Type $\delta / \zeta$} & $P l c 1^{\mathrm{d}}$ & NCU01266 ${ }^{\mathrm{d}}(\mathrm{e}-47)$ & 154928 (e-69/-38/-67/-64/-34/-76/-38/-24-/22) & AtPLC1 (e-15/-17/-10/-10) \\
\hline & & NCU06245 (e-30) & 202996 (e-82/-90/-81/-81/-81/-92/-87/-30/-28) & AtPLC2 (e-15/-20/-11/-12) \\
\hline & & NCU11415 (e-24) & $221032(\mathrm{e}-83 /-94 /-81 /-90 /-86 /-93 /-94 /-32 /-31)$ & AtPLC3 (e-14/-22/-19/-11) \\
\hline & & NCU02175 (e-24) & 216835 (e-65/-120/-116/-134/-127/-139/-113(-39/-37) & AtPLC4 (e-15/-19/-10/-8) \\
\hline & & & 30932 (e-114/-139/-115/-136/-131/-142/-133/-80/-69) & AtPLC5 (e-16/-18/-9/-7) \\
\hline & & & $131223(\mathrm{e}-75 /-84 /-75 /-75 /-72 /-85 /-84 /-44 /-20)$ & AtPLC6 (e-23/-19/-11/-11) \\
\hline & & & $133245(\mathrm{e}-114 /-122 /-111 /-128 /-126 /-130 /-122 /-41 /-39)$ & AtPLC7 (e-28/-9/-11/-11) \\
\hline & & & 1 & AtPLC8 (e-8/-6/-5/-5) \\
\hline & & & & AtPLC9 (e-6/-6/-4/-3) \\
\hline \multicolumn{5}{|c|}{ PI phosphatases with Sac1 domain } \\
\hline \multirow[t]{3}{*}{ Group A } & $\mathrm{Sacl}^{\mathrm{d}}$ & NCU00896 ${ }^{\mathrm{d}, \mathrm{e}}(\mathrm{e}-125)$ & $182250^{\mathrm{f}}(\mathrm{e}-167 /-166 /-161)$ & $\operatorname{AT5G66020}{ }^{\mathrm{e}, \mathrm{f}}(\mathrm{e}-76 /-54)$ \\
\hline & & NCU1330 (e-56) & $196461^{\mathrm{f}}(\mathrm{e}-159 /-157 /-153)$ & AT3G51460 $(\mathrm{e}-69 /-51)$ \\
\hline & & & $\begin{array}{l}154117(\mathrm{e}-149 /-148 /-146) \\
113866(\mathrm{e}-130 /-125 /-122)\end{array}$ & AT3G51830 (e-65/-47) \\
\hline \multirow[t]{2}{*}{ Group B } & Fig $4^{\mathrm{d}}$ & NCU08689 $9^{\mathrm{d}, \mathrm{e}}(\mathrm{e}-189)$ & $145180^{\mathrm{f}}(\mathrm{e}-177 /-179 / 0.0 /-175 / 0.0)$ & 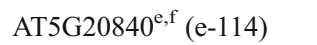 \\
\hline & & & $188826^{\mathrm{f}}(\mathrm{e}-178 / 0.0 / 0.0 /-169 / 0.0)$ & AT3G43220 ${ }^{\mathrm{e}, \mathrm{f}}(\mathrm{e}-113)$ \\
\hline
\end{tabular}


Table 1 (continued)

\begin{tabular}{|c|c|c|c|c|}
\hline Enzyme & S. cerevisiae & N. $\operatorname{crass}^{\mathrm{a}}$ & P. patens ${ }^{\mathrm{b}}$ & A. thaliana $^{\mathrm{c}}$ \\
\hline & & & $127285^{\mathrm{f}}(\mathrm{e}-173 /-180 / 0.0 /-168 / 0.0)$ & AT3G14205, ${ }^{\mathrm{f}}(\mathrm{e}-104)$ \\
\hline & & & $124571^{\mathrm{f}}(\mathrm{e}-178 /-178 / 0.0 /-165 / 0.0)$ & AT1G17340, f $(\mathrm{e}-94)$ \\
\hline & & & & $\mathrm{AT} 1 \mathrm{G} 22630^{\mathrm{f}}(\mathrm{e}-83)$ \\
\hline Group C & / & / & $137140^{\mathrm{f}}(0.0)$ & AT3G59770 $(\mathrm{e}-17)$ \\
\hline \multicolumn{5}{|c|}{ PI phosphatases with Sac1 and 5-PPase domain } \\
\hline & $\operatorname{Inp} 51^{\mathrm{d}}$ & $\begin{array}{l}\text { NCU03792 }{ }^{\mathrm{d}}(\mathrm{e}-35) \\
\text { NCU01047 (e-9) }\end{array}$ & / & / \\
\hline & $\operatorname{Inp} 52^{\mathrm{d}}, \operatorname{Inp} 53^{\mathrm{d}}$ & NCU03298 $(\mathrm{e}-144)$ & l & / \\
\hline \multicolumn{5}{|c|}{ PI phosphatases with 5-PPase domain } \\
\hline & Inp54 & NCU00684 (e-4) & $146379^{\mathrm{f}}(0.0 / 0.0 / 0.0 / 0.0)$ & AT1G65580 $(e-10)$ \\
\hline & & & & AT2G43900 $(\mathrm{e}-8)$ \\
\hline & & & & $\operatorname{AT} 1 G 05630^{f}(e-10)$ \\
\hline & & & & AT2G31830 (e-9) \\
\hline & & & $114940^{\text {f }}(\mathrm{e}-94 /-91 /-84 /-78 /-76 /-74 /-64 /-63 /-63 /-62)$ & AT3G63240 f $(e-7)$ \\
\hline & & & $55067^{\mathrm{f}}(\mathrm{e}-92 /-89 /-84 /-80 /-79 /-84 /-82 /-82 /-68 /-68)$ & AT5G65090 (e-10) \\
\hline & & & $119139^{\mathrm{f}}(\mathrm{e}-99 /-78 /-72 /-82 /-81 /-76 /-85 /-90 /-67 /-69)$ & AT2G37440 (e-10) \\
\hline & & & $147084^{\mathrm{f}}(\mathrm{e}-95 /-87 /-69 /-79 /-79 /-84 /-88 /-88 /-65 /-67)$ & AT2G32010 (e-9) \\
\hline & & & $42353^{\text {f }}(\mathrm{e}-99 /-78 /-73 /-83 /-83 /-77 /-75 /-86 /-67 /-64)$ & AT1G05470 (e-9) \\
\hline & & & $61331^{\mathrm{f}}(\mathrm{e}-93 /-75 /-71 /-87 /-77 /-73 /-92 /-85 /-65 /-67)$ & AT5G04980 (e-11) \\
\hline & & & & AT4G18010 (e-9) \\
\hline & & & & AT1G34120 (e-11) \\
\hline & & & & AT1G71710 (e-9) \\
\hline & & & & AT2G01900 (e-11) \\
\hline & & & 33817 (fragment?) & l \\
\hline & & & 33819 (fragment?) & \\
\hline & & & 33820 (fragment?) & \\
\hline & & & $\begin{array}{l}4897(\mathrm{e}-57) \\
160028(\mathrm{e}-42)\end{array}$ & 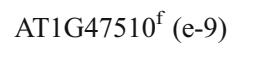 \\
\hline \multicolumn{5}{|c|}{ PI phosphatases with myotubularin domain } \\
\hline & $\mathrm{Ymrl}^{\mathrm{d}}$ & $\mathrm{NCU} 11185^{\mathrm{d}, \mathrm{e}}(\mathrm{e}-78)$ & $71628^{\mathrm{f}}(\mathrm{e}-161 /-141)$ & AT3G10550 e,f $(\mathrm{e}-40)$ \\
\hline & & & $12645^{\mathrm{f}}(\mathrm{e}-171 /-152)$ & $\operatorname{AT} 5 \mathrm{G} 04540^{\mathrm{e}}(\mathrm{e}-41)$ \\
\hline \multicolumn{5}{|c|}{ PI phosphatases with Tensin domain } \\
\hline & & & $14952^{\mathrm{f}}(\mathrm{e}-168 /-162 /-41)$ & AT3G19420 ${ }^{\mathrm{f}}(\mathrm{e}-7)$ \\
\hline & & & $11763^{\mathrm{f}}(\mathrm{e}-175 /-169 /-40)$ & AT3G50110 f (e-6) \\
\hline & & & $173463(\mathrm{e}-104 /-102 /-32)$ & \\
\hline & & & 233117 (e-110/-105/-26) & \\
\hline & Tep $1^{\mathrm{d}}$ & NCU06969, $(\mathrm{e}-14)$ & / & $\operatorname{AT} 5 \mathrm{G} 39400^{\mathrm{e}}(\mathrm{e}-11)$ \\
\hline
\end{tabular}

${ }^{\text {a }}$ E-values in this column correspond to $S$. cerevisiae $-N$. crassa BLASTP comparison

${ }^{\mathrm{b}}$ E-values in this column correspond to $A$. thaliana-P. patens BLASTP comparison

${ }^{\mathrm{c}}$ E-values in this column correspond to $N$. crassa-A. thaliana BLASTP comparison

${ }^{\mathrm{d}}$ Best bidirectional hit for $N$. crassa and $S$. cerevisiae candidate pairs

${ }^{\mathrm{e}}$ Best bidirectional hits for $N$. crassa and A. thaliana candidate pairs

${ }^{\mathrm{f}}$ Best bidirectional hits for $A$. thaliana and $P$. patens candidate pairs

have been identified (Mueller-Roeber and Pical 2002) which can be divided in the two PI 4-kinase subfamilies $\alpha$ and $\beta$ consisting of two members each (Table 1). The eight members of a third A. thaliana PI 4-kinase subfamily $\gamma$ with similaritiy to the yeast PI 4-kinase, Lsb6p (Las17binding 6) (Han et al. 2002), and to mammalian class II PI-kinases (Mueller-Roeber and Pical 2002) have not been shown to harbor PI-kinase activity, but rather act as protein 
kinases (Galvao et al. 2008). In comparison to Mss $4 p$ (multicopy suppressor of stt4) as the only PI4P 5-kinase in yeast, the $A$. thaliana genome contains 11 genes encoding PI4P 5-kinase isoforms (Mueller-Roeber and Pical 2002), and for five of these catalytic activity has been experimentally verified (Elge et al. 2001; Perera et al. 2005; Lee et al. 2007; Ischebeck et al. 2008; Kusano et al. 2008; Sousa et al. 2008; Stenzel et al. 2008). Two subgroups containing AtPIP5K1-AtPIP5K9 and AtPIP5K10/AtPIP5K11 can be differentiated (Table 1), but the functional significance of this sequence diversification in plants is currently unknown. Similar subfamilies can be found in different eukaryotic organisms for enzymes catalyzing most of the reactions of PI-biosynthesis or PI-breakdown. As will be discussed below, it is possible that additional branches of the PI signaling system have evolved as the complexity of organisms has increased. Despite their low abundance (Ferrell and Huestis 1984; Butikofer et al. 1989; König et al. 2007), the complex network of PIs has important roles in eukaryotic signaling cascades (Stevenson et al. 2000; Meijer and Munnik 2003), including those controlling cell polarity (Thole and Nielsen 2008; Heilmann 2009).

Different cellular functions of PIs may be controlled by distinct PI pools

PIs can control many physiological functions in eukaryotic cells. As will be discussed in more detail below, evidence from a number of eukaryotic model systems indicates that PIs affect metabolism by controlling ion transport across membranes, guanine triphosphatase (GTPase) function or localization, cytoskeletal structures, and membrane trafficking. Diverse functionality of PIs in alternative contexts might be achieved through discrete PI pools of different metabolic origin and/or different spatiotemporal localization (Doughman et al. 2003; Santarius et al. 2006; Johnson et al. 2008) that control alternative cellular processes (King et al. 1987; Heilmann et al. 1999; Kost et al. 1999; Heilmann et al. 2001; Doughman et al. 2003; Santarius et al. 2006; König et al. 2007). How independent PI pools are generated and maintained is still unclear. Differences in substrate preferences for CDP-DAG species containing saturated or unsaturated acyl chains have been reported for the PIS isoforms, PIS1 and PIS2 (Löfke et al. 2008). Overexpression of PIS1 or of PIS2 in A. thaliana plants indicates that the enhanced amounts of PtdIns produced by each isoform were channeled into different metabolic routes (Löfke et al. 2008), suggesting that different pools of PIs may exist already at the level of PtdIns, possibly distinguished by their associated fatty acids. This view is supported by animal PIP-kinases and PI phosphatases that have preferences for PI-substrates with certain fatty acid compositions (Carricaburu and Fournier 2001; Schmid et al. 2004). It has also been shown that increased levels of PtdIns4P and PtdIns $(4,5) \mathrm{P}_{2}$ detected in $A$. thaliana after osmotic stress differ in their acyl-chain composition from PtdIns4P and PtdIns(4,5) $\mathrm{P}_{2}$ present under non-stressed conditions (König et al. 2007). In consequence, differences in fatty acid composition may be one factor responsible for the altered lateral mobility of PIs (Mukherjee et al. 1999; Cho et al. 2006) that may lead to interactions with alternative partner proteins (Heilmann 2008). The concept of discrete PI pools is especially important in polar growing cells, because PIs likely have multiple crucial roles in establishing and maintaining polar cell growth, as will be discussed further down.

\section{PI-degradation}

Since PIs are potent messenger molecules, organisms have evolved mechanisms to turn off these signals by either dephosphorylating the inositol polyphosphate headgroup or by cleaving it from the diacylglycerol (DAG) backbone. Especially PtdIns4P and PtdIns $(4,5) \mathrm{P}_{2}$ have been shown to have high turnover rates in plant cells (Meijer et al. 1999; Perera et al. 2002; Im et al. 2007b; Krinke et al. 2007). To understand the complexity of PI biosynthesis and breakdown is therefore a prerequisite for the elucidation of PI functions in polar tip growth.

The $A$. thaliana genome contains multiple genes coding for putative PI phosphatases (Table 1). The suppressor of actin (SAC) family contains nine proteins with similarity to the yeast PI phosphatases Sac1p (Hughes et al. 2000; Foti et al. 2001) and Fig4p (Rudge et al. 2004) that primarily dephosphorylate PtdIns4P and PtdIns $(3,5) \mathrm{P}_{2}$, respectively. SAC1-SAC5 have the highest similarity to Fig4p and at least $\mathrm{SAC} 1$ catalyzes the same reaction as Fig4p (Zhong et al. 2005). A. thaliana SAC6-SAC8 are more closely related to yeast Sac1p, and SAC7 has been recently shown to dephosphorylate mainly PtdIns4P with additional substantial activity towards all other PIs (Thole et al. 2008). SAC9 is unique in its domain structure (Zhong et al. 2004), and even though its enzyme activity has not been reliably determined in in vitro tests. A. thaliana mutants deficient in this protein have constitutively elevated $\operatorname{PtdIns}(4,5) \mathrm{P}_{2}$ levels (Williams et al. 2005).

Three other phosphatases from A. thaliana show sequence similarity to the family of phosphatase and tensin homologue (PTEN) phosphatases known from the mammalian field to act on $\operatorname{PtdIns}(3,4,5) \mathrm{P}_{3}$, as for example PTEN1 (Gupta et al. 2002), while two proteins homologous to mammalian myotubularin are present in the $A$. thaliana genome. However, no enzymatic specificity or cellular function has been assigned to any of these phosphatases.

Another large group of phosphatases with homology to yeast Inp $54 \mathrm{p}$ are present in plants that dephosphorylate 
inositol-polyphosphates at the D-5 position (Zhong et al. 2004; Zhong and Ye 2004). There are 15 genes with unknown functions with similarity to Inp54p in the $A$. thaliana genome (Table 1). While the PI phosphatases of the SAC family dephosphorylate both lipid PIs and soluble inositol polyphosphates and are therefore referred to as type II inositol polyphosphate 5-phosphatases, these enzymes are capable of dephosphorylating only soluble inositol polyphosphates as for example $\mathrm{InsP}_{3}$ and represent type I inositol polyphosphate 5-phosphatases (Berdy et al. 2001).

Phospholipases C (PLCs) cleave phospholipids between the phosphate group and the DAG backbone. While some PLCs are active towards structural phospholipids (nonspecific PLCs) (Nakamura et al. 2005), others only cleave PIs (PI-PLCs), releasing DAG and the respective soluble inositol polyphosphates (Mueller-Roeber and Pical 2002). While in mammals, multiple gene families encoding PIPLCs are present, the $A$. thaliana genome contains only one family of seven members with similarity to mammalian PLCs of the $\zeta$ subfamily (formerly classified among the $\delta$ subfamily) (Tasma et al. 2008). The activity of proteins of this subfamily is regulated through $\mathrm{Ca}^{2+}$ levels (MuellerRoeber and Pical 2002), thus linking PI degradation and DAG/inositol polyphosphate signaling to cellular $\mathrm{Ca}^{2+}$ levels.

Polar tip growth - a complex signaling network, membrane transport, and the cytoskeleton

Polar growth of cells of any type requires the coordination of fundamental functions involved in defining the site of polar growth, delivering material to the growing apex and incorporating this material at its destination (Nelson 2003). The specification of the site of polar growth involves the formation of specialized biological structures, which differentiate the plasma membrane and the cytoplasm of the growing apex from other regions of the cell. Such specializations are reflected in the formation of the "clear zone" of pollen tubes and root hairs (Franklin-Tong 1999; Zonia and Munnik 2009) or the "Spitzenkörper" of fungal hyphae (Steinberg 2007). Long-distance transport of material required for growth as well as factors that establish and maintain polarity depend on the presence of cytoskeletal elements. The final delivery of material to the site of incorporation is achieved along actin fibres and involves the interaction and directed transport of exocytotic vesicles (Fischer et al. 2008). Since only a small proportion of exocytosed membrane area remains in the plasma membrane after vesicles have fused and released their contents, endocytotic recycling of vesicles is an essential element of cell expansion, which also depends on a functional actin cytoskeleton (Samaj et al. 2006).
Control of membrane trafficking by PIs

Roles of PtdIns $4 P$ In yeast and animal cells, PIs are important for secretory vesicle flow from the Golgi to the plasma membrane. An important role in this process has been attributed to PI 4-kinases. Activity of these enzymes has been found in animals (Endemann et al. 1987; Pike 1992), yeast (S. cerevisiae (Flanagan et al. 1993)) but also in plants, such as carrot (Daucus carota) (Okpodu et al. 1995), spinach (Spinacia oleracea (Westergren et al. 1999)) and A. thaliana (Xue et al. 1999). The yeast enzyme, Stt4p (Yoshida et al. 1994), has been shown to localize at the plasma membrane by binding Sfk1p (suppressor of four kinase), a transmembrane spanning protein of unclear function (Audhya and Emr 2002). The roles of the two homologous PI 4-kinases of the A. thaliana $\alpha$ subfamily in polar growth also remain unresolved to date.

More information is available on the two PI 4-kinases representing the $A$. thaliana $\beta$ subfamily (Xue et al. 1999). Mutant analyses have demonstrated that $A$. thaliana PI4K $\beta 1$ has a function in the growth of root hairs and pollen tubes (Preuss et al. 2006; Szumlanski and Nielsen 2009). PI 4-kinases of the $\beta$ subfamily are localized at trans-Golgi vesicles in A. thaliana root hairs (Preuss et al. 2006) and tobacco pollen tubes (Szumlanski and Nielsen 2009). Similar localizations have been observed for homologues in yeast (Walch-Solimena and Novick 1999) and mammals (Olsen et al. 2003). In A. thaliana, it has been proposed that type $\beta$ PI 4-kinases are recruited to trans-Golgi vesicles by the action of the small $G$ protein, RabA4b (Ras associated binding protein $\mathrm{A} 4 \mathrm{~b}$ ) and of AtCBL1 (calcineurin B-like protein 1), a $\mathrm{Ca}^{2+}$-sensing protein (Preuss et al. 2006). An interaction partner similar to AtCBL1, frequenin, has previously been described in yeast and animals (Hendricks et al. 1999; Strahl et al. 2003). The yeast PI 4-kinase Pik1p is essential for membrane trafficking from the Golgi to the plasma membrane. When Pik1p is eliminated, secretion is diminished (Uno et al. 1988; Hama et al. 1999; Walch-Solimena and Novick 1999; Audhya et al. 2000) and abnormal membranous structures called "Berkeley bodies" accumulate in the cytoplasm (Walch-Solimena and Novick 1999; Audhya et al. 2000; Strahl et al. 2005). On the other hand, when PtdIns4P levels are elevated in yeast cells overexpressing Pik1p or in cells deficient in the PI phosphatase, Sac1p, exocytosis of the chitin synthase Chs3p and most likely also of other proteins is enhanced, leading to cell wall defects (Schorr et al. 2001). Thus, the comparison of PI 4-kinase functions of the $\beta$ subfamily in organisms from different eukaryotic kingdoms allows the conclusion that PtdIns4P appears to be universally required for controlling trafficking of secretory vesicles between the Golgi apparatus and the plasma membrane. 
Roles of PtdIns $(4,5) P_{2} \operatorname{PtdIns}(4,5) \mathrm{P}_{2}$ is produced from PtdIns4P by PI4P 5-kinases. PI4P 5-kinases have been found to be associated with the plasma membrane of animal, yeast, and also of $A$. thaliana and tobacco cells using fluorescent reporters (Lee et al. 2007; Ischebeck et al. 2008; Kusano et al. 2008; Sousa et al. 2008; Stenzel et al. 2008). Enzyme activities have, however, been detected not only in enriched plasma membrane preparations (Sommarin and Sandelius 1988; Perera et al. 1999; Heilmann et al. 2001; Kobayashi et al. 2005; Santarius et al. 2006), but also in other subcellular fractions such as the nucleus of mammalian and yeast cells (Ciruela et al. 2000; Audhya and Emr 2003; Santarius et al. 2006), the actin cytoskeleton of yeast and plants (Desrivieres et al. 1998; Doughman et al. 2003; Davis et al. 2007), and endomembranes of animal and plant cells (Whatmore et al. 1996; Heilmann et al. 1999; Im et al. 2007a). The mechanism recruiting PI4P 5kinases to the plasma membrane in plants is unknown; however sphingolipids have been shown to be involved in plasma membrane localization of Mss4p, the only PI4P 5kinase present in yeast (Kobayashi et al. 2005). PtdIns(4,5) $\mathrm{P}_{2}$ generated by Mss $4 \mathrm{p}$ has been proposed to play a role in the fusion of secretory vesicles with the plasma membrane (Strahl and Thorner 2007), because overexpression of Mss $4 p$ can rescue several temperature sensitive mutants defective in proteins of the secretory machinery. Examples are Sec8p (protein with a role in secretion), Sec10p and Sec15p (TerBush et al. 1996; Guo et al. 1999; Hsu et al. 1999), which are all members of the multiprotein exocyst complex, which is required for the tethering of exocytotic vesicles to the plasma membrane. Other examples include the syntaxin-binding protein Sec1p (Aalto et al. 1991; Halachmi and Lev 1996; Carr et al. 1999) and the plasma membrane target soluble $N$-ethylmaleimide sensitive factor attachment receptor, Sec9p (Sollner et al. 1993; Brennwald et al. 1994; Hay and Scheller 1997).

The involvement of PtdIns $(4,5) \mathrm{P}_{2}$ in exocytosis is also conserved in animal cells, where $\operatorname{PtdIns}(4,5) \mathrm{P}_{2}$ also targets the exocyst complex to the plasma membrane ( $\mathrm{He}$ et al. 2007; Liu et al. 2007). In neuronal cells both PtdIns4P and $\operatorname{PtdIns}(4,5) \mathrm{P}_{2}$ stimulate exocytosis by priming dense core vesicles for fusion and by recruiting the protein CAPS (calcium-activated protein for secretion) to the plasma membrane, which is essential for vesicle fusion (Hay and Martin 1993; Hay et al. 1995; Berwin et al. 1998). A similar mechanism has been shown for the exocytosis of insulincontaining vesicles in pancreatic $\beta$-cells (Olsen et al. 2003). Animal PtdIns $(4,5) \mathrm{P}_{2}$ has also been shown to stimulate the formation of SNARE complexes that are required for the fusion of vesicles with their target membranes (Vicogne et al. 2006). Furthermore, both CAPS and synaptotagmin have roles in the SNARE-mediated fusion process and are activated by PIs (Sugita 2008).
The A. thaliana genome contains a total of 35 genes coding for putative exocyst subunits (Ehlert et al. 2006). While the $A$. thaliana genome contains no genes with obvious similarity to CAPS genes, three genes have been found that encode putative synaptotagmin isoforms (Craxton 2004). Subunits of the plant exocyst complex, Sec3/Rth 1 (roothairless1) in Zea mays (Wen et al. 2005) and Sec8 in A. thaliana (Cole et al. 2005), have been found to be involved in the formation of root hairs and pollen tubes, respectively, highlighting their importance in polar tip growth. Even though a putative interaction of these proteins with PtdIns $(4,5) \mathrm{P}_{2}$ has not yet been investigated, $\operatorname{Ptd} \operatorname{Ins}(4,5) \mathrm{P}_{2}$ might be involved in the targeting of the exocyst complex to the plant plasma membrane in analogy to other eukaryotic models, suggesting PtdIns $(4,5) \mathrm{P}_{2}$ as an important regulator of exocytosis in tip growing plant cells. Increased pectin secretion in pollen tubes overproducing $\operatorname{PtdIns}(4,5) \mathrm{P}_{2}$ supports this notion (Ischebeck et al. 2008).

PtdIns $(4,5) \mathrm{P}_{2}$ is not only involved in exocytosis but also plays a crucial role in endocytosis of the plasma membrane. The temperature sensitive yeast mutant $m s s 4^{t s}$, deficient in its only PI4P 5-kinase, displays defects in endocytic uptake (Desrivieres et al. 2002) when shifted to restrictive temperature. Complementary results were obtained with mammalian neuronal cells, where endocytosis is increased, when PtdIns $(4,5) \mathrm{P}_{2}$ levels are enhanced (Cremona et al. 1999), and decreased, when $\operatorname{Ptd} \operatorname{Ins}(4,5) \mathrm{P}_{2}$ levels are reduced (Di Paolo et al. 2004). A possible role of PtdIns $(4,5) \mathrm{P}_{2}$ in endocytosis might relate to the fact that in yeast and in mammalian cells many proteins of the endocytotic machinery are recruited to the plasma membrane by PtdIns $(4,5) \mathrm{P}_{2}$ (Jost et al. 1998; Gaidarov and Keen 1999; Takei et al. 1999; Vallis et al. 1999; D'Hondt et al. 2000; Ford et al. 2001; Itoh et al. 2001; Friesen et al. 2006). Even though association of PtdIns $(4,5) \mathrm{P}_{2}$ with clathrin-coated vesicles during stress-induced endocytosis has recently been shown for plant cells (König et al. 2008), much less is known about membrane trafficking and the roles of PIs in endocytotic processes in plants. In summary, the comparative analysis of PtdIns(4,5) $\mathrm{P}_{2}$ functions in different eukaryotic models suggests that this lipid has a conserved role in defining the sites of vesicle fusion/fission during endo- and exocytosis, most likely through its effects on components of the exocyst complex and components of the membrane fusion machinery. As will be described in more detail below, $\operatorname{Ptd} \operatorname{Ins}(4,5) \mathrm{P}_{2}$ is additionally a regulator of the actin cytoskeleton, which is also of key importance for vesicle transport and membrane trafficking.

Roles of 3-phosphorylated PIs PtdIns can also be phosphorylated at its D3-position by PI 3-kinases. PI 3-kinases from mammals can be grouped in three different classes according to their substrate specificity. Class I PI 3-kinases 
phosphorylate all PI species, including PtdIns, PtdIns4P and PtdIns(4,5) $\mathrm{P}_{2}$ (Vanhaesebroeck et al. 2001). Even though class I enzymes play important roles in animals, there is no evidence for their occurence in plants or fungi (Table 1). Class II PI 3-kinases only phosphorylate PtdIns and PtdIns4P, while enzymes of class III accept only PtdIns as a substrate. Class III PI 3-kinases are typifed by the yeast protein Vps34p (vacuolar protein sorting 34; (Schu et al. 1993)) and are the only PI 3-kinases identified in plants and fungi (Table 1). Mutations in the yeast Vps34 gene have been shown to exhibit severe defects in vacuolar protein sorting. In A. thaliana there is only one gene, AtVPS34, present that encodes a PI 3-kinase (Welters et al. 1994). A. thaliana PI 3-kinase has been implicated in membrane trafficking events during adaptation to salt stress (Leshem et al. 2007). Plant PI 3-kinase has also been reported in the nucleus of carrot cells, specifically at sites of active transcription (Bunney et al. 2000). It has recently been shown that the production of PtdIns3P is important for root hair growth (Lee et al. 2008a), however, the exact roles of PtdIns3P in plant function to date remain unclear.

PI3P 5-kinases phosphorylate PtdIns3P in the D-5 position of the inositol ring (Meijer and Munnik 2003). Data from yeast and animals suggest that 3-phosphorylated PIs have roles in controlling retrograde vesicular trafficking between plasma membrane or early endosomes and the trans-Golgi network (Rutherford et al. 2006; VolpicelliDaley and De Camilli 2007; Dove et al. 2009). Reports of stress-induced formation of PtdIns(3,5) $\mathrm{P}_{2}$ in yeast (Dove et al. 1997; Bonangelino et al. 2002) and the unicellular green alga, Chlamydomonas rheinhardtii (Meijer et al. 1999) upon hyperosmotic challenge might be related to a role in endocytotic trafficking that mediates increased membrane turnover. The $A$. thaliana genome contains four genes encoding putative PI3P 5-kinases (Table 1) (Gaullier et al. 1998). However, no experimental characterization has been reported to date for these plant gene products. The relevance of a recent report on the involvement of PI3P 5-kinases in pollen development of $A$. thaliana is difficult to interpret, as no biochemical characterization of the proteins was performed (Whitley et al. 2009). Thus, the roles of 3-phosphorylated PIs in plants must remain largely speculative at this point.

Control of the actin cytoskeleton by $\operatorname{PtdIns}(4,5) \mathrm{P}_{2}$

Besides the roles of PIs in membrane trafficking, in particular PtdIns $(4,5) \mathrm{P}_{2}$ has intensively been studied with regard to effects on cytoskeletal structures. The dynamic network of actin filaments of eukaryotic cells not only mediates stability, but is also involved in protein and vesicle movement, in cell shaping and cell division, and in sensing and signaling (Wasteneys and Galway 2003). Even though actin can polymerize spontaneously in the presence of ATP, in vivo this polymerization process is regulated by actinbinding proteins (ABPs) that can induce and promote or inhibit polymerization, or can lead to branching or breaking of actin strands. In animals, PtdIns $(4,5) \mathrm{P}_{2}$ can influence actin dynamics by binding to ABPs, thus modulating their activity. After the completion of the A. thaliana genome sequence (Arabidopsis-Genome-Initiative 2000) it became apparent that a number of non-plant ABPs have homologous counterparts in plants (Wasteneys and Yang 2004), whereas other ABPs - for example talin, vitronectin and vinculin - appear to be missing in plants (Wasteneys and Galway 2003). Thus, it can be assumed that some aspects of the plant cytoskeleton are regulated in a similar fashion as in animals, while others may be profoundly different. Increases in $\operatorname{PtdIns}(4,5) \mathrm{P}_{2}$ levels have been shown to have rigidifying effects on the actin cytoskeleton in mammalian cell lines (Shibasaki et al. 1997; Rozelle et al. 2000; Yamamoto et al. 2001) and in yeast (Ojala et al. 2001) that have been attributed to misregulation of ABPs. Since actin depolymerising ABPs, such as cofilin or gelsolin, are inhibited by $\operatorname{PtdIns}(4,5) \mathrm{P}_{2}$ (Hepler et al. 2001; Hussey et al. 2002), an increase of cellular PtdIns(4,5) $\mathrm{P}_{2}$-levels may hyperstabilize the actin cytoskeleton and disrupt its dynamics also in plants.

In both animals and fungi, actin dynamics can be controlled by a number of monomeric GTPases, which are themselves subject to regulation by a number of accessory proteins, including various GTPase activating proteins (GAPs), guanidine nucleotide exchange factors (GEFs) or GDP dissociation inhibitors (GDIs) (Faure and Dagher 2001). The roles of Rho GTPases of the Rac-Rop subfamily, in polar tip growth have been the focus of a number of studies and have been reviewed in depth (de Curtis 2008; Kost 2008). Like other small GTPases, Rac-Rop GTPases are monomers that are active when bound to GTP and inactive in their GDP-bound form. Rac-Rop GTPases localize at the apex of growing pollen tubes and root hairs, and it has been hypothesized that they play a role in membrane trafficking and the organization of the actin cytoskeleton (Kost et al. 1999; Li et al. 1999; Molendijk et al. 2001; Jones et al. 2002; Lee et al. 2008b). It has been demonstrated that PIs exert regulatory effects on GTPase signaling, for instance by binding to and inactivating/sequestering GDIs (Faure et al. 1999; DerMardirossian and Bokoch 2005), leading to increased activation of GTPases. Plants contain multiple isoforms of small GTPases, GAPs, GEFs and GDIs (Kost 2008), and it has been shown that cytoskeletal structures are profoundly affected in plants when components of the GTPase signaling systems are impaired ( $\mathrm{Gu}$ et al. 2003, 2005, 2006; Klahre et al. 2006; Klahre and Kost 2006). In pollen tubes of petunia or tobacco an increase in $\operatorname{Ptd} \operatorname{Ins}(4,5)$ $\mathrm{P}_{2}$ levels induced by a reduction of PLC activity led to a 
disorganization of the actin cytoskeleton accompanied by similar phenotypes as those observed with overproduction of Rac-Rop GTPases (Fig. 2b) (Dowd et al. 2006; Helling et al. 2006). When the levels of PtdIns4P or PtdIns $(4,5) \mathrm{P}_{2}$ are diminished, for example in yeast cells deficient in Stt4p or Mss4p, respectively, the actin cytoskeleton behaves abnormally and cell polarity is lost (Strahl and Thorner 2007). It has been described for mammalian fibroblasts that lowering the amount of free PtdIns $(4,5) \mathrm{P}_{2}$ decreases the adhesion of the cytoskeleton with the plasma membrane, demonstrating that PtdIns $(4,5) \mathrm{P}_{2}$ acts in the attachment of actin to the plasma membrane (Raucher et al. 2000). A. thaliana lines mutated in PIP5K3 (Kusano et al. 2008; Stenzel et al. 2008), PIP5K4 (Lee et al. 2007; Ischebeck et al. 2008; Sousa et al. 2008), PIP5K5 (Ischebeck et al. 2008; Sousa et al. 2008) or PIP5K9 (Lou et al. 2007) have been isolated, but cytoskeletal dynamics in these plants have so far not been investigated. Based on the available data it therefore appears likely that $\operatorname{PtdIns}(4,5) \mathrm{P}_{2}$ controls the actin cytoskeleton through effects on GTPase signaling in plants in a similar manner to that in fungi and animals. While effects of PtdIns $(4,5) \mathrm{P}_{2}$ on actin dynamics by means of ABPs have been demonstrated in plants (Drobak et al. 1994), the extent to which regulation of GTPase signaling by PIs contributes to the control of actin dynamics is currently not clear.

\section{Control of ion channels by $\operatorname{PtdIns}(4,5) \mathrm{P}_{2}$}

Another important function of PIs in eukaryotic cells is the control of ion channels. Transient and localized changes in ion concentrations, especially of $\mathrm{Ca}^{2+}$, are essential for various signal transduction pathways, and one important ligand regulating ion channels is $\operatorname{PtdIns}(4,5) \mathrm{P}_{2}$.
Unlike other proteins that are soluble and are recruited from the cytoplasm to the plasma membrane by their affinity to $\operatorname{PtdIns}(4,5) \mathrm{P}_{2}$, ion channels are transmembrane proteins (Lee 2004). It is presumed that ion channels bind PtdIns $(4,5) \mathrm{P}_{2}$ located in close proximity at the inner leaflet of the plasma membrane via $\mathrm{N}$ - and/or C-terminal binding domains (Suh and Hille 2008). The examination of ion channel regulation by $\operatorname{PtdIns}(4,5) \mathrm{P}_{2}$ in living cells is difficult due to the complex cellular responses to PtdIns $(4,5) \mathrm{P}_{2}$ and because the methods and reagents currently used are of limited specificity (Suh and Hille 2005). Human inward-rectifier $\mathrm{K}^{+}$-channels were the first channels found to be regulated by $\operatorname{PtdIns}(4,5) \mathrm{P}_{2}$, and they are activated by binding this lipid (Hilgemann and Ball 1996). Partial structures are available for this type of channel (Nishida and MacKinnon 2002; Pegan et al. 2005), and structural data and mutagenesis studies have revealed that each of the four subunits of the channel binds $\operatorname{PtdIns}(4,5) \mathrm{P}_{2}$ via six basic residues situated at the $\mathrm{C}$-terminal cytosolic domain (Haider et al. 2007). Neuronal voltage-gated $\mathrm{K}^{+}$-channels are activated in a similar manner (Delmas and Brown 2005; Li et al. 2005), and their PtdIns(4,5) $\mathrm{P}_{2}$ binding sites are suspected to reside in the C-terminal cytosolic domain (Zhang et al. 2003).

Transient receptor potential (TRP) channels are another diverse group of mammalian cation channels that are regulated in their activity by $\operatorname{PtdIns}(4,5) \mathrm{P}_{2}$. This class of ion-channels is particularly interesting because some representatives, such as TRPV5 (Rohacs et al. 2005), are activated while others like TRPL (Estacion et al. 2001) are inhibited by PtdIns $(4,5) \mathrm{P}_{2}$. The regulatory mechanism seems to be similar to that of $\mathrm{K}^{+}$channels (Rohacs 2007). All the channels described so far are of human or animal
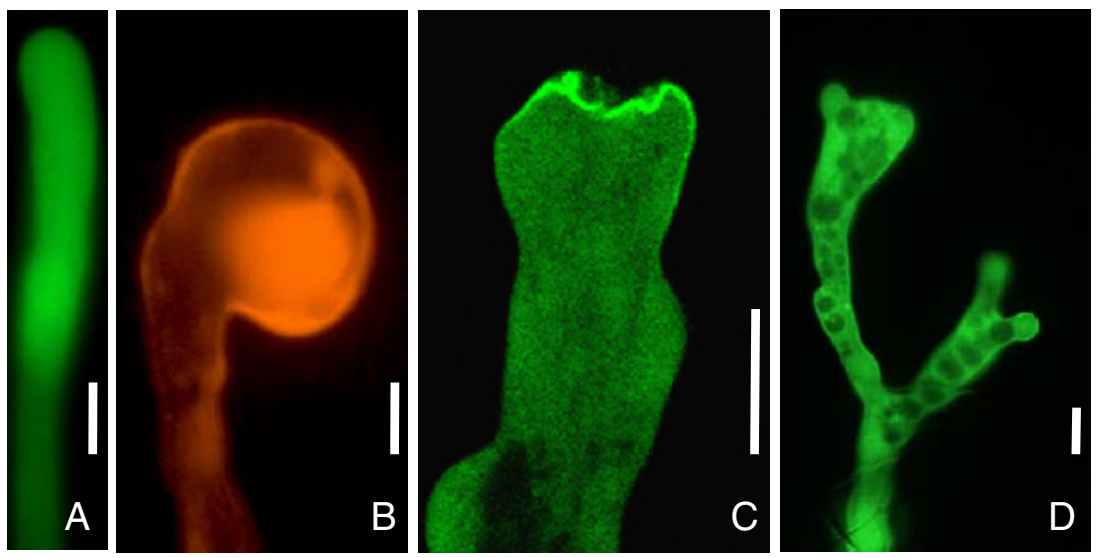

Fig. 2 Morphological alterations of tobacco pollen tubes perturbed in polar signaling. a Unaltered growth of a tobacco pollen tube transiently expressing cytosolic EYFP. b Apical tip swelling of a tobacco pollen tube transiently expressing the small GTPase, RFP:NtRac5. c Apical plasma membrane invaginations during transient expression of the A. thaliana type B PI4P 5-kinase, PIP5K5:EYFP, at high levels. d Tip branching during transient expression of the $A$. thaliana type B PI4P 5-kinase, PIP5K5:EYFP, at intermediate levels. Bars $10 \mu \mathrm{m}$. RFP red fluorescent protein, EYFP enhanced yellow fluorescent protein. Data according to (Klahre et al. 2006) (b) and (Ischebeck et al. 2008) (c, d) 
origin and much less is known about ion channel regulation by PtdIns $(4,5) \mathrm{P}_{2}$ in plants or fungi. It was reported that some shaker-type $\mathrm{K}^{+}$-channels of plant origin are activated in vitro by $\operatorname{PtdIns}(4,5) \mathrm{P}_{2}$ (Liu et al. 2005). It has been proposed that $\operatorname{PtdIns}(4,5) \mathrm{P}_{2}$ plays a role in the inactivation of slow anion channels in guard cells during stomatal opening (Lee et al. 2007). The tobacco outward-rectifying $\mathrm{K}^{+}$-channel has also been demonstrated to be regulated by PtdIns(4,5) $\mathrm{P}_{2}$ (Ma et al. 2009). All channels that have been reported to be regulated by $\operatorname{PtdIns}(4,5) \mathrm{P}_{2}$ are localized at the plasma membrane. Since no $\operatorname{PtdIns}(4,5) \mathrm{P}_{2}$ is present in the ER or in Golgi vesicles, one can assume that these channels remain inactive during their trafficking from the ER via the Golgi to the plasma membrane and are inactivated in the recycling process after endocytosis (Hilgemann et al. 2001). The control of ion channels by PIs, thus, appears a common trait of eukaryotic cells, which is, however, of unclear relevance for polar cell growth.

Effects on polar tip growth through perturbation of the PI system

A. thaliana plants mutated in the PIP5K3 gene, which is specifically expressed in root epidermal cells, have very short root hairs (Kusano et al. 2008; Stenzel et al. 2008), whereas overexpression of PIP5K3 leads to a loss of apical polarity and aberrant root hair morphology (Kusano et al. 2008; Stenzel et al. 2008). Similarly, the regulation of PtdIns4P levels is also important for normal root hair growth, since plants mutated in type $\beta$ PI 4-kinases or the PtdIns4P-degrading phosphatase, RHD4, display aberrant root hair morphology (Preuss et al. 2006; Thole et al. 2008). It has also been shown that strong expression of the fluorescence-tagged pleckstrin homology-domain of the human PLC $\delta 1$, which specifically binds $\operatorname{PtdIns}(4,5) \mathrm{P}_{2}$, resulted in a growth arrest of pollen tubes (Kost et al. 1999). Thus, severe and characteristic polarity defects have been reported for pollen tubes upon perturbation of the PI system or of Rac-Rop GTPase signaling (Fig. 2), and these phenotypes might aid the elucidation of the mechanisms by which PIs contribute to the control of polar tip growth. One characteristic morphological effect observed in pollen tubes that results from perturbing the complex interplay of signaling factors is tip swelling (Fig. 2b). Loss of polarity and apolar tip swelling has been reported after interfering with the GTPase signaling network (Gu et al. 2003, 2005, 2006; Klahre et al. 2006; Klahre and Kost 2006) or by overaccumulation of $\operatorname{PtdIns}(4,5) \mathrm{P}_{2}$ after interfering with its PLC-mediated breakdown (Dowd et al. 2006). It is still a matter of debate as to what tip swelling can tell us about the molecular basis of polar tip growth. Recently, it has been proposed that tip swelling of pollen tubes is a result of an expanded area of exocytosis and defective endocytosis
(Kost 2008). It must be noted, however, that a pollen tube does not necessarily grow in the direction of exocytosis, but rather in the direction where the plastic cell wall yields most easily to the mechanical force of the internal turgor pressure. In contrast, it has also been speculated that turgor pressure (which can reach 0.2 MPa in pollen tubes) is the sole force responsible for cell expansion (Benkert et al. 1997; Bosch et al. 2005; Zonia et al. 2006; Kroeger et al. 2008).

The contribution of the actin cytoskeleton to the mechanical force driving polar expansion of plant cells is a matter of ongoing debate. In animal cells, actin filaments and cables can clearly influence cell shape in a mechanical manner (Pollard et al. 2000). Depolymerization of the actin cytoskeleton of pollen tubes by the toxin latrunculin B results in slower growth, a reduced ability to invade a mechanical obstacle (Gossot and Geitmann 2007) and, at higher concentrations of the drug, in growth arrest (Vidali et al. 2001), leading Gossot and Geitmann to propose that actin filaments do exert a mechanical force that drives pollen tube elongation (Gossot and Geitmann 2007). In addition, pollen tubes treated with the actin-stabilizing drugs jasplakinolide or chondramide B also exhibited modest tip swelling (Cardenas et al. 2008), which possibly resulted from the force applied by the stabilized actin cytoskeleton in all directions of the pollen tube tip (Fig. 3a-c). Thus, normal and polar elongation of untreated pollen tubes may be, at least in part, driven by actin dynamics directed towards the pollen tube apex.

Considering the importance of the actin cytoskeleton for tip polarity, a very interesting concept is that PIs might inhibit GDIs by recruiting them to the plasma membrane (Faure et al. 1999; DerMardirossian and Bokoch 2005), leading to increased activation of Rac-type G-proteins, perturbation of the actin cytoskeleton and ultimately tip swelling. In consequence, it has been proposed that GDIs are an important point of interdependency between G-proteins and PI signaling in polar growing cells (Kost 2008).

So far, the mechanisms by which PIs control polar tip growth are unclear, but they are clearly part of the complex interplay of signaling factors required for cell polarity. This is exemplified by a loss of polar growth and tip swelling in pollen tubes after inhibition of PI-PLC-mediated PtdIns $(4,5) \mathrm{P}_{2}$ degradation (Dowd et al. 2006; Helling et al. 2006). This treatment is also accompanied by a distortion of the cytoskeleton (Dowd et al. 2006) and increased intracellular $\mathrm{Ca}^{2+}$-levels (Dowd et al. 2006).

While the actin cytoskeleton is a key factor determining cell polarity and controlling of polar growth, the restriction of cell expansion by the cell wall is another (Fig. 3d-f). In pollen tubes the cell wall of the most apical 10-20 $\mu \mathrm{m}$ consists primarily of pectin, and is kept flexible through the activity of pectin methyl esterases (PMEs) (Bosch et al. 2005; Parre and Geitmann 2005; Tian et al. 2006). How 
A

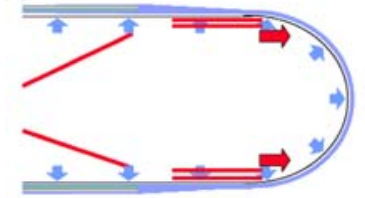

B

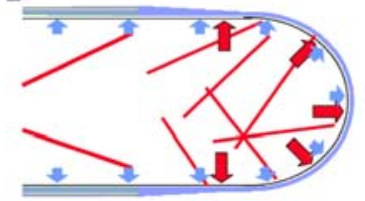

C

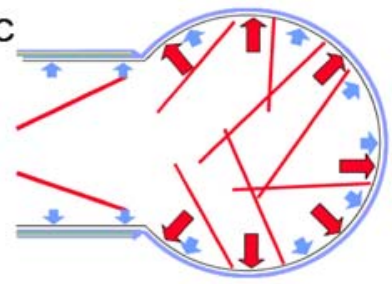

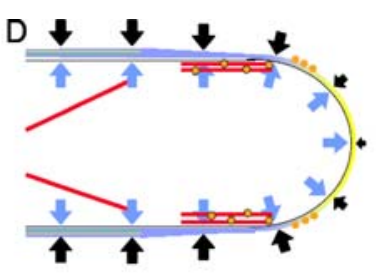

E

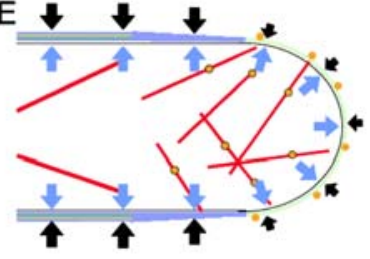

$\mathrm{F}$

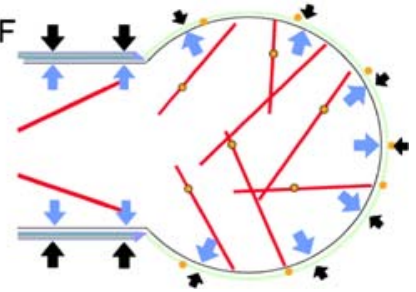

Fig. 3 Alternative models to explain tip swelling. a-c Model for pollen tube tip swelling considering the actin cytoskeleton as a major force in cell expansion. The cell wall is composed of pectin (blue) and is additionally strengthened by callose and cellulose in the pollen tube shank (green and yellow). Cellular expansion is driven by turgor pressure (blue arrows) and a mechanical force (red arrows) deriving from the cytoskeleton (red bars). a Normal pollen tube growth. The actin cytoskeleton, especially the actin fringe (parallel subapical red lines), drives cell expansion only in the direction of growth. b Disorganisation of the actin cytoskeleton due to a perturbed PI system. The force exerted now by the cytoskeleton acts equally in all directions resulting in tip swelling (c). Tip swelling is restricted to the apex, because the cell wall is inflexible in the shank due to cellulose and callose. $\mathbf{d}-\mathbf{f}$ Model for pollen tube tip swelling considering only turgor pressure and cell wall plasticity, but no direct mechanical force by the actin cytoskeleton as factors of polar growth. Cellular expansion is driven by turgor pressure counteracted by the mechanical force of the cell wall (black arrows). d Normal pollen tube growth. Pectin occurring in its methylated form at the very tip (indicated by yellow color) is flexible and the resistance against the turgor is smaller (indicated by a small black arrow). PME is transported in exocytotic vesicles (orange dots encircled in black) along the actin fringe and secreted in the subapical region (orange dots), where it converts pectin to its rigid, deesterified, $\mathrm{Ca}^{2+}$ bound form (indicated by blue color), resulting in a stronger counteracting force of the cell wall (longer black arrows). e After disturbance of the cytoskeleton PME distribution is disorganized, resulting in a uniformly de-esterified and flexible apical cell wall, indicated by smaller equally long arrows for the counteracting force of the cell wall. f As a consequence, the cell wall expands in all directions, resulting in tip swelling (f)

PMEs - and other proteins modulating cell wall plasticityare targeted to their site of action in the pollen tube is still a matter of debate (Rockel et al. 2008). Even though the role of the actin fringe, a ring of longitudinal cortical actin fibres found in pollen tubes, is not well understood (LovyWheeler et al. 2005), this fragile structure may be involved

in the vectorial transport of secretory vesicles containing cell wall material and/or cell wall-modifying enzymes to the plasma membrane (Fig. 3d) (Chen et al. 2007). If the actin fringe is perturbed, the balance of rigid and flexible regions in the apical cell wall could be altered, because enzymes such as PMEs are no longer targeted to the exactly required region (Rockel et al. 2008) and might now be more randomly distributed (Fig. 3e). A possible consequence is that the apical cell wall becomes uniformly flexible and turgor pressure may expand the pollen tube in this region evenly in all directions, ultimately leading to tip swelling (Fig. 3f). A possible unifying explanation for tip swelling is that perturbed PI metabolism not only modulates the cytoskeleton but also turgor pressure. Evidence for this hypothesis comes from the report that phospholipid and PI signals can regulate the cell volume of pollen tubes (Zonia et al. 2002, 2006). Thus, studying turgor and ion fluxes of pollen tubes overaccumulating $\operatorname{PtdIns}(4,5) \mathrm{P}_{2}$ may lead to a better understanding of aberrant tip swelling.

Exocytosis of pectin at the pollen tube tip has to be tightly regulated to preserve the plasticity of the apical cell wall, which is crucial for pollen tube elongation. Tobacco pollen tubes overexpressing type B PI4P 5-kinases demonstrated characteristic morphological changes, such as pollen tube branching or "protoplast trapping" (Fig. 2b, c), and exhibited massive incorporation of pectin into the apical cell wall (Ischebeck et al. 2008). Since type B PI4P 5-kinases localize at the apical plasma membrane of pollen tubes (Ischebeck et al. 2008; Sousa et al. 2008) and pectin is secreted at the pollen tube tip (Bosch and Hepler 2005; Tian et al. 2006), the increased abundance of $\operatorname{PtdIns}(4,5) \mathrm{P}_{2}$ may be the cause for the excessive exocytosis of pectin, and the observed phenotypes might be explained by an increased rate of exocytosis of pectin (Fig. 4). If secretion of pectin is strongly increased, the apical cell wall becomes thicker and less flexible (Fig. 4a-d). As a consequence, turgor pressure and/or the actin cytoskeleton may no longer be strong enough to expand the cell wall and pollen tube elongation will cease. Since exocytosis is now uncoupled from tube growth, vesicle fusion to the apical plasma membrane will continue even after cell expansion has ceased. These fusion events lead not only to cell wall deposition, but also to increased apical deposition of membrane area. If the turgor pressure-driven expansion of the protoplast within a rigidified cell wall is inhibited, excessive membrane area may invaginate (Fig. 4d), resulting in a "trapped protoplast" (Ischebeck et al. 2008). Tip branching may be the result of ongoing tip growth, in which pectin deposition is not strong enough to terminate growth, but only alters the plasticity of the most apical cell wall, resulting in two zones of flexible cell wall divided by a more rigid region (Fig. $4 \mathrm{e}-\mathrm{g}$ ). The concept that increased pectin deposition in pollen tubes that overproduce PtdIns $(4,5) \mathrm{P}_{2}$ is the result of increased exocy- 


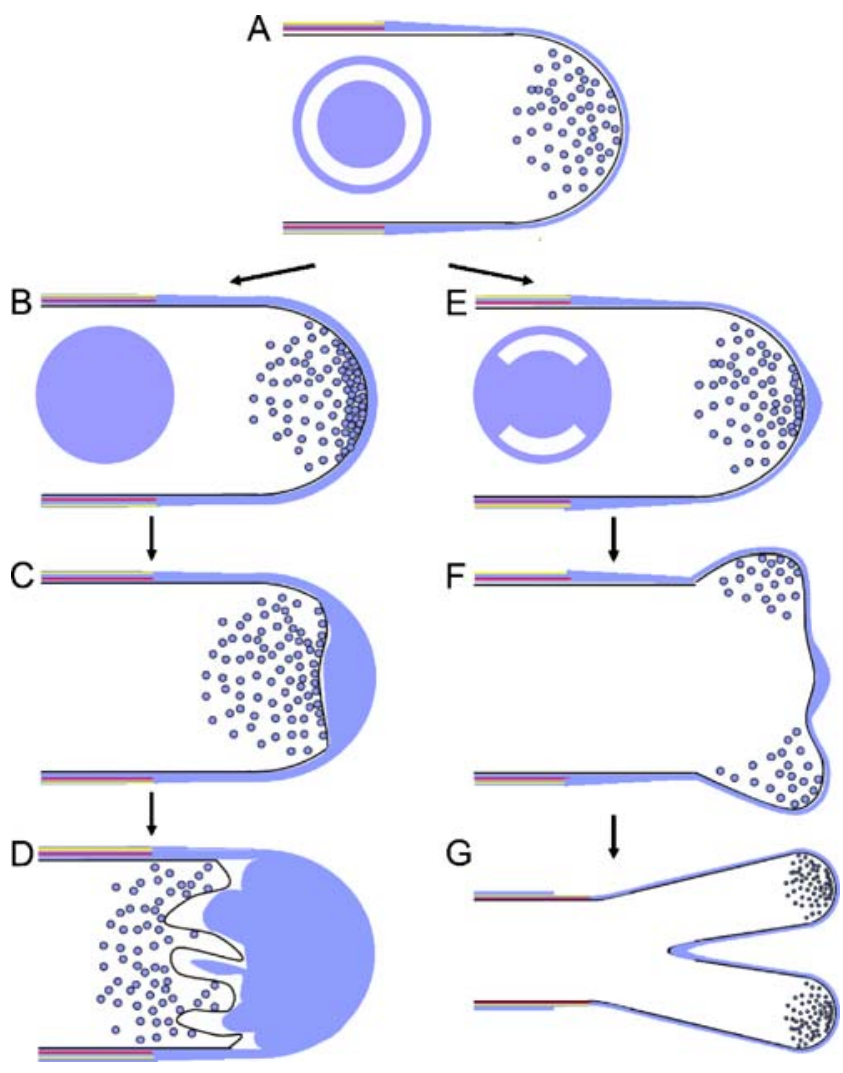

Fig. 4 Model for the pollen tube "trapped protoplast" and branching phenotypes. a Normal pollen tube growth. Secretion of pectincontaining exocytotic vesicles is tightly regulated to sustain cell wall plasticity. The disk indicates a ring-shaped zone of flexible cell wall (white). b If pectin secretion is increased due to strong overexpression of type B PI4P 5-kinases, cellular expansion is inhibited due to the thickening of the cell wall. The solid blue disk indicates the absence of a zone of flexible cell wall. c Continuous exocytosis leads to additional cell wall accumulation at the pollen tube apex. d The plasma membrane of the "trapped protoplast" folds inwards. e When secretion is increased due to type B PI4P 5-kinase overexpression, pectin occasionally blocks apical expansion. The disk indicates zones of flexible cell wall (white) alternating with zones of inflexible cell wall (blue). f Pollen tube expansion in subapical regions with a cell wall more flexible than that at the very apex leads to splitting of the pollen tube tip. g Growth continues simultaneously at both tips, resulting in the branched pollen tube phenotype

tosis raises the question, whether $\operatorname{PtdIns}(4,5) \mathrm{P}_{2}$ is also responsible for regulating the secretion of other cell wall components or extracellular matrix components in other eukaryotes.

Polar growth of fungal hyphae: is it similar to polar growth of plant cells?

Assuming that the basic mechanisms of polar tip growth are shared, similar effects of PIs should be encountered if organisms of different kingdoms are compared. Moving along the phylogenetic tree away from higher plants, data from related organisms confirm this concept. For instance, the predominant protonemal expression of one PtdInsmonophosphate kinase (Saavedra et al. 2009) suggests a role for PI signaling in polar tip growth in the moss Physcomitrella patens. With increasing phylogenetic distance to plants and mosses, polar growing cells reminiscent in structure to plant root hairs, pollen tubes or moss protonemata are the hyphae of filamentous fungi, such as Neurospora crassa or Candida albicans. Functional evidence for the involvement of PI signaling in these different organisms comes from mutant studies, and it has been reported that mutations in enzymes relevant for PI signaling are impaired in hyphal growth, for instance in C. albicans (Badrane et al. 2008). Importantly, extensive screening of mutagenized $N$. crassa spores for strains deficient in hyphal morphogenesis has yielded numerous hits for key enzymes of PI signaling, including PI 4- and PI4P 5-kinases (Seiler and Plamann 2003). An interesting example for the development of new hypotheses based on a comparative biological approach is the proposed function of the poorly understood phospholipid PtdIns5P (Lecompte et al. 2008). Lecompte and coworkers deduced a function for PtdIns5P in membrane trafficking between late endosomal compartments and the plasma membrane based on the comparison of 39 eukaryotic genomes with regard to the occurrence of genes corresponding to enzymes of PtdIns5P biosynthesis or breakdown. Interestingly, these findings confirm a general similarity between the PI systems of plants and fungi (Lecompte et al. 2008). While the machineries for defining the site of growth, the intracellular delivery of material to this site and the fusion of cargo vesicles and release at this destination might be similar between organisms of different kingdoms, particular details may well be different. For instance, the cell walls of pollen tubes and fungal hyphae are composed of different building blocks which nonetheless may be secreted by similar means.

Data available on the roles of PIs in polar growth indicate that the PI system has been important for polar growth already in the common ancestor of fungi, mosses and higher land plants, dating back more than an estimated 400 million years (Rensing et al. 2008). Comparative approaches will aid the understanding of the roles of PIs in the control of cell polarity and polar tip growth. An analysis of the published genomes of $S$. cerevisiae, $N$. crassa, P. patens, and A. thaliana for key enzymes of PI metabolism (Table 1) indicates that all players required for the regulation of polar tip growth are present in these relevant examples of the fungal and plant kingdoms.

From the phylogenetic distribution of PI signaling enzymes a number of general conclusions can be drawn. First, it is obvious that the formation of 3-phosphorylated PIs, such as PtdIns3P or PtdIns $(3,5) \mathrm{P}_{2}$, is mediated by only very few enzymes in fungi and plants, compared to a much greater number of enzymes in mammals. Second, the 
formation of $\operatorname{PtdIns}(4,5) \mathrm{P}_{2}$, is much more streamlined in fungi and lower plants than in $A$. thaliana. While both fungal genomes contain only one PI4P 5-kinase, generation of PtdIns $(4,5) \mathrm{P}_{2}$ requires 11 PI4P 5-kinases of two distinct subgroups in $A$. thaliana. However, the moss $P$. patens has a repertoire of only two PI4P 5-kinases of the same subgroup as the fungal ones, and is thus more similar to fungi than higher plants. The situation for PI 4 kinases is more complex in that the highly extended $\gamma$ subfamily, which is represented by eight $A$. thaliana and four P. patens proteins, is most likely not a family of lipid, but protein kinases in plants (Galvao et al. 2008). Nevertheless, the number of fungal PI 4-kinases seems more streamlined in having only two kinases of non-redundent function, while four PI 4-kinases are present in both plants. Similarly, in both plants three subgroups containing nine Sac domaincontaining phosphatases can be distinguished, while corresponding sequences can be found in fungi only for two subgroups (Table 1). The family of 5-phosphatase domain-containing phosphatases is also greatly enlarged in plants in comparison to the situation in fungi (Table 1). However, phosphatases with Sac and 5-phosphatase domain are present in fungi and animals, but absent in plants. It is also becoming apparent that PLC isoforms in plants have diversified by three potential gene duplications, but the resulting sequences cannot be assigned to any particular fungal counterpart. Third, when basic requirements for polar tip growth are considered, the comparison between the fungi $S$. cerevisiae and $N$. crassa suggests substantially more complex PI regulation of hyphal versus budding growth. Interestingly, the added complexity proposed for $N$. crassa is not based on more complex patterns for PI biosynthesis, but rather on an increased number of PLCs and PI phosphatases (four versus one and nine versus seven, in $N$. crassa and $S$. cerevisiae, respectively, counting the paralogous proteins Imp52 and Imp53, which have overlapping functions in yeast, as one phosphatase). This trend continues in lower plants that have a number of kinases similar to the two fungi, but a highly increased repertoire of phosphatases. Overall, it appears that polar tip growth in $N$. crassa or in plants is accompanied by increased complexity of PI signaling compared to that found in yeast, which is achieved by diversified means for PI biosynthesis and breakdown (in plants) or by additional regulation of PI breakdown only (in N. crassa). Similarly, between P. patens and A. thaliana the number of PI 4-kinases and PI4P 5-kinases appears to rise with increasing complexity of the organism.

\section{Conclusions}

The data summarized in this article suggest that PIs are important for polar tip growth by regulating the machinery establishing and maintaining a polarized cell. It is important to emphasize that PIs do not perform one regulatory function, but rather are linked in multiple places to the complex network of GTPases, $\mathrm{Ca}^{2+}$, other ion-fluxes and lipid and soluble signals. Key aspects of PI regulation are clearly the control of the dynamic actin cytoskeleton and that of localized vesicle trafficking and fusion. Other aspects, such as ion channels, have not been studied in detail in the context of polar tip growth, but might prove to be very important. Based on the available data, the authors favor the hypothesis that different functions of PIs might be orchestrated by spatiotemporal separation of functional PI pools. However, to date it remains unclear how such pools may be physically arranged. Recent evidence suggests that independent PI pools might have their origin in PI-intermediates channeled towards certain interaction partners within a membrane, but this concept is not easily accessible to current experimental tools. Advances in the visualization of specific lipids, while prone to a number of known and inherent artifacts (Heilmann 2009), have enabled the decoration of punctate domains in the apical plasma membrane of polar growing cells that are likely enriched in sterols (Skirpan et al. 2006; Liu et al. 2009). Such microdomains have been shown to be important for the function of the PI system (Fairn et al. 2007; Johnson et al. 2008) and might provide microenvironments with particular enzyme complements that control certain aspects of polarity, whereas freely diffusible PIs might serve other functions.

Overall, many questions regarding the roles of PIs in the control of polar tip growth must remain unanswered at this time. The physiological situations in a differentiated tissue cell and in a polar growing cell are notably different, and many ideas presented here must be subjected to experimental verification. The evolutionary conservation of the machinery for polar tip growth throughout eukaryotic kingdoms can, however, serve as a basis for comparative biology. Future experiments directed towards a comprehensive elucidation of polar growth mechanisms should, thus, take into consideration that different aspects of polar growth have been studied in different model systems, providing an impression of different aspects of the - at first approximation - same machinery. While the complexity of the relevant signaling networks is enormous, an interdisciplinary view might help to solve at least some of the puzzles.

Acknowledgements IH and TI gratefully acknowledge financial support through an Emmy Noether grant from the German Research Foundation (DFG, to $\mathrm{IH}$ ). SS was financially supported through the DFG Research Center of Molecular Physiology of the Brain and the DFG Priority Program SPP1111.

Conflict of interest The authors declare that they have no conflict of interest. 
Open Access This article is distributed under the terms of the Creative Commons Attribution Noncommercial License which permits any noncommercial use, distribution, and reproduction in any medium, provided the original author(s) and source are credited.

\section{References}

Aalto MK, Ruohonen L, Hosono K, Keranen S (1991) Cloning and sequencing of the yeast Saccharomyces cerevisiae SEC1 gene localized on chromosome IV. Yeast 7:643-650

Anderson RA, Boronenkov IV, Doughman SD, Kunz J, Loijens JC (1999) Phosphatidylinositol phosphate kinases, a multifaceted family of signaling enzymes. J Biol Chem 274:9907-9910

Arabidopsis-Genome-Initiative (2000) Analysis of the genome sequence of the flowering plant Arabidopsis thaliana. Nature 408:796-815

Audhya A, Emr SD (2002) Stt4 PI 4-kinase localizes to the plasma membrane and functions in the Pkc1-mediated MAP kinase cascade. Dev Cell 2:593-605

Audhya A, Emr SD (2003) Regulation of PI4, 5P2 synthesis by nuclear-cytoplasmic shuttling of the Mss4 lipid kinase. Embo J 22:4223-4236

Audhya A, Foti M, Emr SD (2000) Distinct roles for the yeast phosphatidylinositol 4-kinases, Stt4p and Pik1p, in secretion, cell growth, and organelle membrane dynamics. Mol Biol Cell 11:2673-2689

Badrane H, Nguyen MH, Cheng S, Kumar V, Derendorf H, Iczkowski KA, Clancy CJ (2008) The Candida albicans phosphatase Inp51p interacts with the $\mathrm{EH}$ domain protein Irs $4 \mathrm{p}$, regulates phosphatidylinositol-4, 5-bisphosphate levels and influences hyphal formation, the cell integrity pathway and virulence. Microbiology 154:3296-3308

Benkert R, Obermeyer G, Bentrup FW (1997) The turgor pressure of growing lily pollen tubes. Protoplasma 198:1-8

Berdy SE, Kudla J, Gruissem W, Gillaspy GE (2001) Molecular characterization of At5PTase1, an inositol phosphatase capable of terminating inositol trisphosphate signaling. Plant Physiol 126:801-810

Berwin B, Floor E, Martin TF (1998) CAPS (mammalian UNC-31) protein localizes to membranes involved in dense-core vesicle exocytosis. Neuron 21:137-145

Bonangelino CJ, Nau JJ, Duex JE, Brinkman M, Wurmser AE, Gary JD, Emr SD, Weisman LS (2002) Osmotic stress-induced increase of phosphatidylinositol 3, 5-bisphosphate requires Vac14p, an activator of the lipid kinase Fab1p. J Cell Biol 156:1015-1028

Bosch M, Hepler PK (2005) Pectin methylesterases and pectin dynamics in pollen tubes. Plant Cell 17:3219-3226

Bosch M, Cheung AY, Hepler PK (2005) Pectin methylesterase, a regulator of pollen tube growth. Plant Physiol 138:1334-1346

Brennwald P, Kearns B, Champion K, Keranen S, Bankaitis V, Novick P (1994) Sec9 is a SNAP-25-like component of a yeast SNARE complex that may be the effector of Sec4 function in exocytosis. Cell 79:245-258

Bunney TD, Watkins PA, Beven AF, Shaw PJ, Hernandez LE, Lomonossoff GP, Shanks M, Peart J, Drobak BK (2000) Association of phosphatidylinositol 3-kinase with nuclear transcription sites in higher plants. Plant Cell 12:1679-1688

Butikofer P, Lin ZW, Kuypers FA, Scott MD, Xu CM, Wagner GM, Chiu DT, Lubin B (1989) Chlorpromazine inhibits vesiculation, alters phosphoinositide turnover and changes deformability of ATP-depleted RBCs. Blood 73:1699-1704

Cardenas L, Lovy-Wheeler A, Kunkel JG, Hepler PK (2008) Pollen tube growth oscillations and intracellular calcium levels are reversibly modulated by actin polymerization. Plant Physiol 146:1611-1621
Carr CM, Grote E, Munson M, Hughson FM, Novick PJ (1999) Sec1p binds to SNARE complexes and concentrates at sites of secretion. J Cell Biol 146:333-344

Carricaburu V, Fournier B (2001) Phosphoinositide fatty acids regulate phosphatidylinositol 5-kinase, phospholipase $\mathrm{C}$ and protein kinase C activities. Eur J Biochem 268:1238-1249

Chen T, Teng N, Wu X, Wang Y, Tang W, Samaj J, Baluska F, Lin J (2007) Disruption of actin filaments by latrunculin B affects cell wall construction in Picea meyeri pollen tube by disturbing vesicle trafficking. Plant Cell Physiol 48:19-30

Cho H, Kim YA, Ho WK (2006) Phosphate number and acyl chain length determine the subcellular location and lateral mobility of phosphoinositides. Mol Cells 22:97-103

Ciruela A, Hinchliffe KA, Divecha N, Irvine RF (2000) Nuclear targeting of the beta isoform of type II phosphatidylinositol phosphate kinase (phosphatidylinositol 5-phosphate 4-kinase) by its alpha-helix 7. Biochem J 346(Pt 3):587-591

Cole RA, Synek L, Zarsky V, Fowler JE (2005) SEC8, a subunit of the putative Arabidopsis exocyst complex, facilitates pollen germination and competitive pollen tube growth. Plant Physiol 138:2005-2018

Collin S, Justin AM, Cantrel C, Arondel V, Kader JC (1999) Identification of AtPIS, a phosphatidylinositol synthase from Arabidopsis. Eur J Biochem 262:652-658

Craxton M (2004) Synaptotagmin gene content of the sequenced genomes. BMC Genomics 5:43

Cremona O, Di Paolo G, Wenk MR, Luthi A, Kim WT, Takei K, Daniell L, Nemoto Y, Shears SB, Flavell RA, McCormick DA, De Camilli P (1999) Essential role of phosphoinositide metabolism in synaptic vesicle recycling. Cell 99:179-188

Davis AJ, Im YJ, Dubin JS, Tomer KB, Boss WF (2007) Arabidopsis phosphatidylinositol phosphate kinase 1 binds F-actin and recruits phosphatidylinositol 4-kinase beta1 to the actin cytoskeleton. J Biol Chem 282:14121-14131

de Curtis I (2008) Functions of Rac GTPases during neuronal development. Dev Neurosci 30:47-58

Delmas P, Brown DA (2005) Pathways modulating neural KCNQ/M (Kv7) potassium channels. Nat Rev Neurosci 6:850-862

Demmel L, Beck M, Klose C, Schlaitz AL, Gloor Y, Hsu PP, Havlis J, Shevchenko A, Krause E, Kalaidzidis Y, Walch-Solimena C (2008) Nucleocytoplasmic shuttling of the Golgi phosphatidylinositol 4-kinase pik1 is regulated by $14-3-3$ proteins and coordinates Golgi function with cell growth. Mol Biol Cell 19:1046-1061

DerMardirossian C, Bokoch GM (2005) GDIs: central regulatory molecules in Rho GTPase activation. Trends Cell Biol 15:356-363

Desrivieres S, Cooke FT, Parker PJ, Hall MN (1998) MSS4, a phosphatidylinositol-4-phosphate 5-kinase required for organization of the actin cytoskeleton in Saccharomyces cerevisiae. J Biol Chem 273:15787-15793

Desrivieres S, Cooke FT, Morales-Johansson H, Parker PJ, Hall MN (2002) Calmodulin controls organization of the actin cytoskeleton via regulation of phosphatidylinositol $(4,5)$-bisphosphate synthesis in Saccharomyces cerevisiae. Biochem J 366:945-951

D'Hondt K, Heese-Peck A, Riezman H (2000) Protein and lipid requirements for endocytosis. Annu Rev Genet 34:255-295

Di Paolo G, Moskowitz HS, Gipson K, Wenk MR, Voronov S, Obayashi M, Flavell R, Fitzsimonds RM, Ryan TA, De Camilli P (2004) Impaired PtdIns(4, 5)P2 synthesis in nerve terminals produces defects in synaptic vesicle trafficking. Nature 431:415-422

Doughman RL, Firestone AJ, Anderson RA (2003) Phosphatidylinositol phosphate kinases put PI4, 5P(2) in its place. J Membr Biol 194:77-89

Dove SK, Cooke FT, Douglas MR, Sayers LG, Parker PJ, Michell RH (1997) Osmotic stress activates phosphatidylinositol-3, 5bisphosphate synthesis. Nature 390:187-192 
Dove SK, Dong K, Kobayashi T, Williams FK, Michell RH (2009) Phosphatidylinositol 3, 5-bisphosphate and Fablp/PIKfyve underPPIn endo-lysosome function. Biochem J 419:1-13

Dowd PE, Coursol S, Skirpan AL, Kao TH, Gilroy S (2006) Petunia phospholipase $\mathrm{c} 1$ is involved in pollen tube growth. Plant Cell 18:1438-1453

Drobak BK, Watkins PAC, Valenta R, Dove SK, Lloyd CW, Staiger CJ (1994) Inhibition of plant plasma membrane phosphoinositide phospholipase $\mathrm{C}$ by the actin-binding protein, profilin. Plant $\mathrm{J}$ 6:389-400

Drobak BK, Dewey RE, Boss WF (1999) Phosphoinositide kinases and the synthesis of polyphosphoinositides in higher plant cells. Int Rev Cytol 189:95-130

Ehlert A, Weltmeier F, Wang X, Mayer CS, Smeekens S, VicenteCarbajosa J, Droge-Laser W (2006) Two-hybrid protein-protein interaction analysis in Arabidopsis protoplasts: establishment of a heterodimerization map of group C and group S bZIP transcription factors. Plant J 46:890-900

Elge S, Brearley C, Xia HJ, Kehr J, Xue HW, Mueller-Roeber B (2001) An Arabidopsis inositol phospholipid kinase strongly expressed in procambial cells: synthesis of $\operatorname{PtdIns}(4,5) \mathrm{P} 2$ and $\operatorname{PtdIns}(3,4,5) \mathrm{P} 3$ in insect cells by 5-phosphorylation of precursors. Plant J 26:561-571

Endemann G, Dunn SN, Cantley LC (1987) Bovine brain contains two types of phosphatidylinositol kinase. Biochemistry 26:68456852

Estacion M, Sinkins WG, Schilling WP (2001) Regulation of Drosophila transient receptor potential-like (TrpL) channels by phospholipase C-dependent mechanisms. J Physiol 530:1-19

Fairn GD, Curwin AJ, Stefan CJ, McMaster CR (2007) The oxysterol binding protein Kes $1 p$ regulates Golgi apparatus phosphatidylinositol4-phosphate function. Proc Natl Acad Sci U S A 104:15352-15357

Faure J, Dagher MC (2001) Interactions between Rho GTPases and Rho GDP dissociation inhibitor (Rho-GDI). Biochimie 83:409-414

Faure J, Vignais PV, Dagher MC (1999) Phosphoinositide-dependent activation of Rho A involves partial opening of the RhoA/RhoGDI complex. Eur J Biochem 262:879-889

Ferrell JE Jr, Huestis WH (1984) Phosphoinositide metabolism and the morphology of human erythrocytes. J Cell Biol 98:1992-1998

Fischer R, Zekert N, Takeshita N (2008) Polarized growth in fungiinterplay between the cytoskeleton, positional markers and membrane domains. Mol Microbiol 68:813-826

Fischl AS, Carman GM (1983) Phosphatidylinositol biosynthesis in Saccharomyces cerevisiae: purification and properties of microsome-associated phosphatidylinositol synthase. J Bacteriol 154:304-311

Flanagan CA, Schnieders EA, Emerick AW, Kunisawa R, Admon A, Thorner J (1993) Phosphatidylinositol 4-kinase: gene structure and requirement for yeast cell viability. Science 262:1444-1448

Ford MG, Pearse BM, Higgins MK, Vallis Y, Owen DJ, Gibson A, Hopkins CR, Evans PR, McMahon HT (2001) Simultaneous binding of PtdIns $(4,5) \mathrm{P} 2$ and clathrin by AP1 80 in the nucleation of clathrin lattices on membranes. Science 291:1051-1055

Foti M, Audhya A, Emr SD (2001) Sac1 lipid phosphatase and Stt4 phosphatidylinositol 4-kinase regulate a pool of phosphatidylinositol 4-phosphate that functions in the control of the actin cytoskeleton and vacuole morphology. Mol Biol Cell 12:2396-2411

Franklin-Tong VE (1999) Signaling and the modulation of pollen tube growth. Plant Cell 11:727-738

Friesen H, Humphries C, Ho Y, Schub O, Colwill K, Andrews B (2006) Characterization of the yeast amphiphysins Rvs161p and Rvs167p reveals roles for the Rvs heterodimer in vivo. Mol Biol Cell 17:1306-1321

Gaidarov I, Keen JH (1999) Phosphoinositide-AP-2 interactions required for targeting to plasma membrane clathrin-coated pits. J Cell Biol 146:755-764
Galvao RM, Kota U, Soderblom EJ, Goshe MB, Boss WF (2008) Characterization of a new family of protein kinases from Arabidopsis containing phosphoinositide 3/4-kinase and ubiquitin-like domains. Biochem J 409:117-127

Gascard P, Tran D, Sauvage M, Sulpice JC, Fukami K, Takenawa T, Claret M, Giraud F (1991) Asymmetric distribution of phosphoinositides and phosphatidic acid in the human erythrocyte membrane. Biochim Biophys Acta 1069:27-36

Gaullier JM, Simonsen A, D'Arrigo A, Bremnes B, Stenmark H, Aasland R (1998) FYVE fingers bind PtdIns(3)P. Nature 394:432-433

Gossot O, Geitmann A (2007) Pollen tube growth: coping with mechanical obstacles involves the cytoskeleton. Planta 226:405-416

Gu Y, Vernoud V, Fu Y, Yang Z (2003) ROP GTPase regulation of pollen tube growth through the dynamics of tip-localized F-actin. J Exp Bot 54:93-101

Gu Y, Fu Y, Dowd P, Li S, Vernoud V, Gilroy S, Yang Z (2005) A Rho family GTPase controls actin dynamics and tip growth via two counteracting downstream pathways in pollen tubes. J Cell Biol 169:127-138

Gu Y, Li S, Lord EM, Yang Z (2006) Members of a novel class of Arabidopsis Rho guanine nucleotide exchange factors control Rho GTPase-dependent polar growth. Plant Cell 18:366-381

Guo W, Roth D, Walch-Solimena C, Novick P (1999) The exocyst is an effector for $\operatorname{Sec} 4 p$, targeting secretory vesicles to sites of exocytosis. EMBO J 18:1071-1080

Gupta R, Ting JT, Sokolov LN, Johnson SA, Luan S (2002) A tumor suppressor homolog, AtPTEN1, is essential for pollen development in Arabidopsis. Plant Cell 14:2495-2507

Haider S, Tarasov AI, Craig TJ, Sansom MS, Ashcroft FM (2007) Identification of the PIP2-binding site on Kir6.2 by molecular modelling and functional analysis. EMBO J 26:3749-3759

Halachmi N, Lev Z (1996) The Sec1 family: a novel family of proteins involved in synaptic transmission and general secretion. J Neurochem 66:889-897

Hama H, Schnieders EA, Thorner J, Takemoto JY, DeWald DB (1999) Direct involvement of phosphatidylinositol 4-phosphate in secretion in the yeast Saccharomyces cerevisiae. J Biol Chem 274:34294-34300

Han GS, Audhya A, Markley DJ, Emr SD, Carman GM (2002) The Saccharomyces cerevisiae LSB6 gene encodes phosphatidylinositol 4-kinase activity. J Biol Chem 277:47709-47718

Hay JC, Martin TF (1993) Phosphatidylinositol transfer protein required for ATP-dependent priming of $\mathrm{Ca}(2+)$-activated secretion. Nature 366:572-575

Hay JC, Scheller RH (1997) SNAREs and NSF in targeted membrane fusion. Curr Opin Cell Biol 9:505-512

Hay JC, Fisette PL, Jenkins GH, Fukami K, Takenawa T, Anderson RA, Martin TF (1995) ATP-dependent inositide phosphorylation required for $\mathrm{Ca}(2+)$-activated secretion. Nature 374:173-177

He B, Xi F, Zhang X, Zhang J, Guo W (2007) Exo70 interacts with phospholipids and mediates the targeting of the exocyst to the plasma membrane. Embo J 26:4053-4065

Heilmann I (2008) Tails wagging the dogs - on phosphoinositides and their fatty acyl moieties. Plant Signal Behav 3:768-771

Heilmann I (2009) Using genetic tools to understand plant phosphoinositide signalling. Trends Plant Sci 14:171-179

Heilmann I, Perera IY, Gross W, Boss WF (1999) Changes in phosphoinositide metabolism with days in culture affect signal transduction pathways in Galdieria sulphuraria. Plant Physiol 119:1331-1339

Heilmann I, Perera IY, Gross W, Boss WF (2001) Plasma membrane phosphatidylinositol 4, 5-bisphosphate levels decrease with time in culture. Plant Physiol 126:1507-1518

Helling D, Possart A, Cottier S, Klahre U, Kost B (2006) Pollen tube tip growth depends on plasma membrane polarization mediated by tobacco PLC3 activity and endocytic membrane recycling. Plant Cell 18:3519-3534 
Hendricks KB, Wang BQ, Schnieders EA, Thorner J (1999) Yeast homologue of neuronal frequenin is a regulator of phosphatidylinositol-4-OH kinase. Nat Cell Biol 1:234-241

Hepler PK, Vidali L, Cheung AY (2001) Polarized cell growth in higher plants. Annu Rev Cell Dev Biol 17:159-187

Hilgemann DW, Ball R (1996) Regulation of cardiac Na+,Ca2+ exchange and KATP potassium channels by PIP2. Science 273:956-959

Hilgemann DW, Feng S, Nasuhoglu C (2001) The complex and intriguing lives of PIP2 with ion channels and transporters. Sci STKE 2001:RE19

Hsu SC, Hazuka CD, Foletti DL, Scheller RH (1999) Targeting vesicles to specific sites on the plasma membrane: the role of the sec6/8 complex. Trends Cell Biol 9:150-153

Hughes WE, Cooke FT, Parker PJ (2000) Sac phosphatase domain proteins. Biochem J 350:337-352

Hussey PJ, Allwood EG, Smertenko AP (2002) Actin-binding proteins in the Arabidopsis genome database: properties of functionally distinct plant actin-depolymerizing factors/cofilins. Philos Trans R Soc Lond B Biol Sci 357:791-798

Im YJ, Davis AJ, Perera IY, Johannes E, Allen NS, Boss WF (2007a) The N-terminal membrane occupation and recognition nexus domain of Arabidopsis phosphatidylinositol phosphate kinase 1 regulates enzyme activity. J Biol Chem 282:5443-5452

Im YJ, Perera IY, Brglez I, Davis AJ, Stevenson-Paulik J, Phillippy BQ, Johannes E, Allen NS, Boss WF (2007b) Increasing plasma membrane phosphatidylinositol(4, 5)bisphosphate biosynthesis increases phosphoinositide metabolism in Nicotiana tabacum. Plant Cell 19:1603-1616

Ischebeck T, Stenzel I, Heilmann I (2008) Type B phosphatidylinositol-4phosphate 5-kinases mediate pollen tube growth in Nicotiana tabacum and Arabidopsis by regulating apical pectin secretion. Plant Cell 20:3312-3330

Itoh T, Koshiba S, Kigawa T, Kikuchi A, Yokoyama S, Takenawa T (2001) Role of the ENTH domain in phosphatidylinositol-4, 5bisphosphate binding and endocytosis. Science 291:1047-1051

Jackson M, Crick DC, Brennan PJ (2000) Phosphatidylinositol is an essential phospholipid of mycobacteria. J Biol Chem 275:3009230099

Johnson CM, Chichili GR, Rodgers W (2008) Compartmentalization of phosphatidylinositol 4, 5-bisphosphate signaling evidenced using targeted phosphatases. J Biol Chem 283:29920-29928

Jones MA, Shen JJ, Fu Y, Li H, Yang Z, Grierson CS (2002) The Arabidopsis Rop2 GTPase is a positive regulator of both root hair initiation and tip growth. Plant Cell 14:763-776

Jost M, Simpson F, Kavran JM, Lemmon MA, Schmid SL (1998) Phosphatidylinositol-4, 5-bisphosphate is required for endocytic coated vesicle formation. Curr Biol 8:1399-1402

Justin AM, Hmyene A, Kader JC, Mazliak P (1995) Compared selectivities of the phosphatidylinositol-synthase from maize coleoptiles either in microsomal membranes or after solubilization. Biochim Biophys Acta 1255:161-166

Justin AM, Kader JC, Collin S (2002) Phosphatidylinositol synthesis and exchange of the inositol head are catalysed by the single phosphatidylinositol synthase 1 from Arabidopsis. Eur J Biochem 269:2347-2352

King CE, Stephens LR, Hawkins PT, Guy GR, Michell RH (1987) Multiple metabolic pools of phosphoinositides and phosphatidate in human erythrocytes incubated in a medium that permits rapid transmembrane exchange of phosphate. Biochem $\mathrm{J}$ 244:209-217

Klahre U, Kost B (2006) Tobacco RhoGTPase ACTIVATING PROTEIN1 spatially restricts signaling of RAC/Rop to the apex of pollen tubes. Plant Cell 18:3033-3046

Klahre U, Becker C, Schmitt AC, Kost B (2006) Nt-RhoGDI2 regulates Rac/Rop signaling and polar cell growth in tobacco pollen tubes. Plant J 46:1018-1031
Kobayashi T, Takematsu H, Yamaji T, Hiramoto S, Kozutsumi Y (2005) Disturbance of sphingolipid biosynthesis abrogates the signaling of Mss4, phosphatidylinositol-4-phosphate 5-kinase, in yeast. J Biol Chem 280:18087-18094

König S, Mosblech A, Heilmann I (2007) Stress-inducible and constitutive phosphoinositide pools have distinct fatty acid patterns in Arabidopsis thaliana. FASEB J 21:1958-1967

König S, Ischebeck T, Lerche J, Stenzel I, Heilmann I (2008) Salt stressinduced association of phosphatidylinositol-4, 5-bisphosphate with clathrin-coated vesicles in plants. Biochem J 415:387-399

Kost B (2008) Spatial control of Rho (Rac-Rop) signaling in tipgrowing plant cells. Trends Cell Biol 18:119-127

Kost B, Lemichez E, Spielhofer P, Hong Y, Tolias K, Carpenter C, Chua NH (1999) Rac homologues and compartmentalized phosphatidylinositol 4, 5-bisphosphate act in a common pathway to regulate polar pollen tube growth. J Cell Biol 145:317-330

Krinke O, Ruelland E, Valentova O, Vergnolle C, Renou JP, Taconnat L, Flemr M, Burketova L, Zachowski A (2007) Phosphatidylinositol 4-kinase activation is an early response to salicylic acid in Arabidopsis suspension cells. Plant Physiol 144:1347-1359

Kroeger JH, Geitmann A, Grant M (2008) Model for calcium dependent oscillatory growth in pollen tubes. J Theor Biol 253:363-374

Kusano H, Testerink C, Vermeer JEM, Tsuge T, Shimada H, Oka A, Munnik T, Aoyama T (2008) The Arabidopsis phosphatidylinositol phosphate 5-kinase PIP5K3 is a key regulator of root hair tip growth. Plant Cell 20:367-380

Lecompte O, Poch O, Laporte J (2008) PtdIns5P regulation through evolution: roles in membrane trafficking? Trends Biochem Sci 33:453-460

Lee AG (2004) How lipids affect the activities of integral membrane proteins. Biochim Biophys Acta 1666:62-87

Lee Y, Kim YW, Jeon BW, Park KY, Suh SJ, Seo J, Kwak JM, Martinoia E, Hwang I (2007) Phosphatidylinositol 4, 5bisphosphate is important for stomatal opening. Plant J 52:803816

Lee Y, Bak G, Choi Y, Chuang WI, Cho HT (2008a) Roles of phosphatidylinositol 3-kinase in root hair growth. Plant Physiol 147:624-635

Lee YJ, Szumlanski A, Nielsen E, Yang Z (2008b) Rho-GTPasedependent filamentous actin dynamics coordinate vesicle targeting and exocytosis during tip growth. J Cell Biol 181:1155-1168

Leshem Y, Seri L, Levine A (2007) Induction of phosphatidylinositol 3-kinase-mediated endocytosis by salt stress leads to intracellular production of reactive oxygen species and salt tolerance. Plant J 51:185-197

Li H, Lin Y, Heath RM, Zhu MX, Yang Z (1999) Control of pollen tube tip growth by a Rop GTPase-dependent pathway that leads to tip-localized calcium influx. Plant Cell 11:1731-1742

Li Y, Gamper N, Hilgemann DW, Shapiro MS (2005) Regulation of Kv7 (KCNQ) K+ channel open probability by phosphatidylinositol 4, 5-bisphosphate. J Neurosci 25:9825-9835

Liu K, Li L, Luan S (2005) An essential function of phosphatidylinositol phosphates in activation of plant shaker-type $\mathrm{K}^{+}$channels. Plant J 42:433-443

Liu J, Zuo X, Yue P, Guo W (2007) Phosphatidylinositol 4, 5bisphosphate mediates the targeting of the exocyst to the plasma membrane for exocytosis in mammalian cells. Mol Biol Cell 18:4483-4492

Liu P, Li RL, Zhang L, Wang QL, Niehaus K, Baluska F, Samaj J, Lin JX (2009) Lipid microdomain polarization is required for NADPH oxidase-dependent ROS signaling in Picea meyeri pollen tube tip growth. Plant J 60:303-313

Löfke C, Ischebeck T, König S, Freitag S, Heilmann I (2008) Alternative metabolic fates of phosphatidylinositol produced by 
PI-synthase isoforms in Arabidopsis thaliana. Biochem $\mathrm{J}$ 413:115-124

Lou Y, Gou JY, Xue HW (2007) PIP5K9, an Arabidopsis phosphatidylinositol monophosphate kinase, interacts with a cytosolic invertase to negatively regulate sugar-mediated root growth. Plant Cell 19:163-181

Lovy-Wheeler A, Wilsen KL, Baskin TI, Hepler PK (2005) Enhanced fixation reveals the apical cortical fringe of actin filaments as a consistent feature of the pollen tube. Planta 221:95-104

Ma X, Shor O, Diminshtein S, Yu L, Im YJ, Perera I, Lomax A, Boss WF, Moran N (2009) Phosphatidylinositol (4, 5)bisphosphate inhibits $\mathrm{K}+$-efflux channel activity in NT1 tobacco cultured cells. Plant Physiol 149:1127-1140

Meijer HJ, Munnik T (2003) Phospholipid-based signaling in plants. Annu Rev Plant Biol 54:265-306

Meijer HJ, Divecha N, van den Ende H, Musgrave A, Munnik T (1999) Hyperosmotic stress induces rapid synthesis of phosphatidyl-Dinositol 3, 5-bisphosphate in plant cells. Planta 208:294-298

Molendijk AJ, Bischoff F, Rajendrakumar CS, Friml J, Braun M, Gilroy S, Palme K (2001) Arabidopsis thaliana Rop GTPases are localized to tips of root hairs and control polar growth. EMBO J 20:2779-2788

Mueller-Roeber B, Pical C (2002) Inositol phospholipid metabolism in Arabidopsis. Characterized and putative isoforms of inositol phospholipid kinase and phosphoinositide-specific phospholipase C. Plant Physiol 130:22-46

Mukherjee S, Soe TT, Maxfield FR (1999) Endocytic sorting of lipid analogues differing solely in the chemistry of their hydrophobic tails. J Cell Biol 144:1271-1284

Nakamura Y, Awai K, Masuda T, Yoshioka Y, Takamiya K, Ohta H (2005) A novel phosphatidylcholine-hydrolyzing phospholipase $\mathrm{C}$ induced by phosphate starvation in Arabidopsis. J Biol Chem 280:7469-7476

Nelson WJ (2003) Adaptation of core mechanisms to generate cell polarity. Nature 422:766-774

Nikawa J, Kodaki T, Yamashita S (1987) Primary structure and disruption of the phosphatidylinositol synthase gene of Saccharomyces cerevisiae. J Biol Chem 262:4876-4881

Nishida M, MacKinnon R (2002) Structural basis of inward rectification: cytoplasmic pore of the $\mathrm{G}$ protein-gated inward rectifier GIRK1 at 1.8 A resolution. Cell 111:957-965

Ojala PJ, Paavilainen V, Lappalainen P (2001) Identification of yeast cofilin residues specific for actin monomer and PIP2 binding. Biochemistry 40:15562-15569

Okpodu CM, Gross W, Burkhart W, Boss WF (1995) Purification and characterization of a soluble phosphatidylinositol 4-kinase from carrot suspension culture cells. Plant Physiol 107:491-500

Olsen HL, Hoy M, Zhang W, Bertorello AM, Bokvist K, Capito K, Efanov AM, Meister B, Thams P, Yang SN, Rorsman P, Berggren PO, Gromada J (2003) Phosphatidylinositol 4-kinase serves as a metabolic sensor and regulates priming of secretory granules in pancreatic beta cells. Proc Natl Acad Sci U S A 100:5187-5192

Parre E, Geitmann A (2005) Pectin and the role of the physical properties of the cell wall in pollen tube growth of Solanum chacoense. Planta 220:582-592

Parries GS, Hokin-Neaverson M (1984) Phosphatidylinositol synthase from canine pancreas: solubilization by n-octyl glucopyranoside and stabilization by manganese. Biochemistry 23:4785-4791

Pegan S, Arrabit C, Zhou W, Kwiatkowski W, Collins A, Slesinger PA, Choe S (2005) Cytoplasmic domain structures of Kir2.1 and Kir3.1 show sites for modulating gating and rectification. Nat Neurosci 8:279-287

Perera IY, Heilmann I, Boss WF (1999) Transient and sustained increases in inositol 1, 4, 5-trisphosphate precede the differential growth response in gravistimulated maize pulvini. Proc Natl Acad Sci U S A 96:5838-5843
Perera IY, Love J, Heilmann I, Thompson WF, Boss WF (2002) Upregulation of phosphoinositide metabolism in tobacco cells constitutively expressing the human type I inositol polyphosphate 5-phosphatase. Plant Physiol 129:1795-1806

Perera IY, Davis AJ, Galanopoulou D, Im YJ, Boss WF (2005) Characterization and comparative analysis of Arabidopsis phosphatidylinositol phosphate 5-kinase 10 reveals differences in Arabidopsis and human phosphatidylinositol phosphate kinases. FEBS Lett 579:3427-3432

Pike LJ (1992) Phosphatidylinositol 4-kinases and the role of polyphosphoinositides in cellular regulation. Endocr Rev 13:692-706

Pollard TD, Blanchoin L, Mullins RD (2000) Molecular mechanisms controlling actin filament dynamics in nonmuscle cells. Annu Rev Biophys Biomol Struct 29:545-576

Preuss ML, Schmitz AJ, Thole JM, Bonner HK, Otegui MS, Nielsen E (2006) A role for the RabA4b effector protein PI-4Kbeta1 in polarized expansion of root hair cells in Arabidopsis thaliana. J Cell Biol 172:991-998

Raucher D, Stauffer T, Chen W, Shen K, Guo S, York JD, Sheetz MP, Meyer T (2000) Phosphatidylinositol 4, 5-bisphosphate functions as a second messenger that regulates cytoskeleton-plasma membrane adhesion. Cell 100:221-228

Rensing SA, Lang D, Zimmer AD, Terry A, Salamov A, Shapiro H, Nishiyama T, Perroud PF, Lindquist EA, Kamisugi Y, Tanahashi T, Sakakibara K, Fujita T, Oishi K, Shin IT, Kuroki Y, Toyoda A, Suzuki Y, Hashimoto S, Yamaguchi K, Sugano S, Kohara Y, Fujiyama A, Anterola A, Aoki S, Ashton N, Barbazuk WB, Barker E, Bennetzen JL, Blankenship R, Cho SH, Dutcher SK, Estelle M, Fawcett JA, Gundlach H, Hanada K, Heyl A, Hicks KA, Hughes J, Lohr M, Mayer K, Melkozernov A, Murata T, Nelson DR, Pils B, Prigge M, Reiss B, Renner T, Rombauts S, Rushton PJ, Sanderfoot A, Schween G, Shiu SH, Stueber K, Theodoulou FL, Tu H, Van de Peer Y, Verrier PJ, Waters E, Wood A, Yang L, Cove D, Cuming AC, Hasebe M, Lucas S, Mishler BD, Reski R, Grigoriev IV, Quatrano RS, Boore JL (2008) The Physcomitrella genome reveals evolutionary insights into the conquest of land by plants. Science 319:64-69

Rockel N, Wolf S, Kost B, Rausch T, Greiner S (2008) Elaborate spatial patterning of cell-wall PME and PMEI at the pollen tube tip involves PMEI endocytosis, and reflects the distribution of esterified and de-esterified pectins. Plant J 53:133-143

Rohacs T (2007) Regulation of TRP channels by PIP(2). Pflugers Arch 453:753-762

Rohacs T, Lopes CM, Michailidis I, Logothetis DE (2005) PI(4, 5)P2 regulates the activation and desensitization of TRPM8 channels through the TRP domain. Nat Neurosci 8:626-634

Rozelle AL, Machesky LM, Yamamoto M, Driessens MH, Insall RH, Roth MG, Luby-Phelps K, Marriott G, Hall A, Yin HL (2000) Phosphatidylinositol 4, 5-bisphosphate induces actin-based movement of raftenriched vesicles through WASP-Arp2/3. Curr Biol 10:311-320

Rudge SA, Anderson DM, Emr SD (2004) Vacuole size control: regulation of $\operatorname{PtdIns}(3,5) \mathrm{P} 2$ levels by the vacuole-associated Vac14-Fig4 complex, a PtdIns(3, 5)P2-specific phosphatase. Mol Biol Cell 15:24-36

Rutherford AC, Traer C, Wassmer T, Pattni K, Bujny MV, Carlton JG, Stenmark H, Cullen PJ (2006) The mammalian phosphatidylinositol 3-phosphate 5-kinase (PIKfyve) regulates endosome-to-TGN retrograde transport. J Cell Sci 119:3944-3957

Saavedra L, Balbi V, Dove SK, Hiwatashi Y, Mikami K, Sommarin M (2009) Characterization of phosphatidylinositol phosphate kinases from the moss Physcomitrella patens: PpPIPK1 and PpPIPK2. Plant Cell Physiol 50:595-609

Samaj J, Muller J, Beck M, Bohm N, Menzel D (2006) Vesicular trafficking, cytoskeleton and signalling in root hairs and pollen tubes. Trends Plant Sci 11:594-600 
Santarius M, Lee CH, Anderson RA (2006) Supervised membrane swimming: small G-protein lifeguards regulate PIPK signalling and monitor intracellular $\operatorname{PtdIns}(4,5) \mathrm{P} 2$ pools. Biochem $\mathrm{J}$ 398:1-13

Schmid AC, Wise HM, Mitchell CA, Nussbaum R, Woscholski R (2004) Type II phosphoinositide 5-phosphatases have unique sensitivities towards fatty acid composition and head group phosphorylation. FEBS Lett 576:9-13

Schorr M, Then A, Tahirovic S, Hug N, Mayinger P (2001) The phosphoinositide phosphatase Sac1p controls trafficking of the yeast Chs3p chitin synthase. Curr Biol 11:1421-1426

Schu PV, Takegawa K, Fry MJ, Stack JH, Waterfield MD, Emr SD (1993) Phosphatidylinositol 3-kinase encoded by yeast VPS34 gene essential for protein sorting. Science 260:88-91

Seiler S, Plamann M (2003) The genetic basis of cellular morphogenesis in the filamentous fungus Neurospora crassa. Mol Biol Cell 14:4352-4364

Shelton SN, Barylko B, Binns DD, Horazdovsky BF, Albanesi JP, Goodman JM (2003) Saccharomyces cerevisiae contains a type II phosphoinositide 4-kinase. Biochem J 371:533-540

Shibasaki Y, Ishihara H, Kizuki N, Asano T, Oka Y, Yazaki Y (1997) Massive actin polymerization induced by phosphatidylinositol-4phosphate 5-kinase in vivo. J Biol Chem 272:7578-7581

Skirpan AL, Dowd PE, Sijacic P, Jaworski CJ, Gilroy S, Kao TH (2006) Identification and characterization of PiORP1, a Petunia oxysterol-binding-protein related protein involved in receptorkinase mediated signaling in pollen, and analysis of the ORP gene family in Arabidopsis. Plant Mol Biol 61:553-565

Sollner T, Whiteheart SW, Brunner M, Erdjument-Bromage H, Geromanos S, Tempst P, Rothman JE (1993) SNAP receptors implicated in vesicle targeting and fusion. Nature 362:318-324

Sommarin M, Sandelius AS (1988) Phosphatidylinositol and phosphatidylinositol phosphate kinases in plant plasma membranes. Biochim Biophys Acta 958:268-278

Sousa E, Kost B, Malho R (2008) Arabidopsis phosphatidylinositol-4monophosphate 5-kinase 4 regulates pollen tube growth and polarity by modulating membrane recycling. Plant Cell 20:3050 3064

Steinberg G (2007) Hyphal growth: a tale of motors, lipids, and the Spitzenkorper. Eukaryot Cell 6:351-360

Stenzel I, Ischebeck T, König S, Holubowska A, Sporysz M, Hause B, Heilmann I (2008) The type B phosphatidylinositol-4-phosphate 5-kinase 3 is essential for root hair formation in Arabidopsis thaliana. Plant Cell 20:124-141

Stevenson JM, Perera IY, Heilmann I, Persson S, Boss WF (2000) Inositol signaling and plant growth. Trends Plant Sci 5:252-258

Strahl T, Thorner J (2007) Synthesis and function of membrane phosphoinositides in budding yeast, Saccharomyces cerevisiae. Biochim Biophys Acta 1771:353-404

Strahl T, Grafelmann B, Dannenberg J, Thorner J, Pongs O (2003) Conservation of regulatory function in calcium-binding proteins: human frequenin (neuronal calcium sensor-1) associates productively with yeast phosphatidylinositol 4-kinase isoform, Pik1. J Biol Chem 278:49589-49599

Strahl T, Hama H, DeWald DB, Thorner J (2005) Yeast phosphatidylinositol 4-kinase, Pik1, has essential roles at the Golgi and in the nucleus. J Cell Biol 171:967-979

Sugita S (2008) Mechanisms of exocytosis. Acta Physiol (Oxf) 192:185-193

Suh BC, Hille B (2005) Regulation of ion channels by phosphatidylinositol 4, 5-bisphosphate. Curr Opin Neurobiol 15:370-378

Suh BC, Hille B (2008) PIP2 is a necessary cofactor for ion channel function: how and why? Annu Rev Biophys 37:175-195

Szumlanski AL, Nielsen E (2009) The Rab GTPase RabA4d regulates pollen tube tip growth in Arabidopsis thaliana. Plant Cell 21:526-544
Takei K, Slepnev VI, Haucke V, De Camilli P (1999) Functional partnership between amphiphysin and dynamin in clathrinmediated endocytosis. Nat Cell Biol 1:33-39

Takenawa T, Egawa K (1977) CDP-diglyceride:inositol transferase from rat liver. Purification and properties. J Biol Chem 252: $5419-5423$

Tasma IM, Brendel V, Whitham SA, Bhattacharyya MK (2008) Expression and evolution of the phosphoinositide-specific phospholipase C gene family in Arabidopsis thaliana. Plant Physiol Biochem 46:627-637

TerBush DR, Maurice T, Roth D, Novick P (1996) The Exocyst is a multiprotein complex required for exocytosis in Saccharomyces cerevisiae. EMBO J 15:6483-6494

Thole JM, Nielsen E (2008) Phosphoinositides in plants: novel functions in membrane trafficking. Curr Opin Plant Biol 11:620-631

Thole JM, Vermeer JE, Zhang Y, Gadella TW Jr, Nielsen E (2008) Root hair defective4 encodes a phosphatidylinositol-4-phosphate phosphatase required for proper root hair development in Arabidopsis thaliana. Plant Cell 20:381-395

Tian GW, Chen MH, Zaltsman A, Citovsky V (2006) Pollen-specific pectin methylesterase involved in pollen tube growth. Dev Biol 294:83-91

Uno I, Fukami K, Kato H, Takenawa T, Ishikawa T (1988) Essential role for phosphatidylinositol 4, 5-bisphosphate in yeast cell proliferation. Nature 333:188-190

Vallis Y, Wigge P, Marks B, Evans PR, McMahon HT (1999) Importance of the pleckstrin homology domain of dynamin in clathrin-mediated endocytosis. Curr Biol 9:257-260

Vanhaesebroeck B, Leevers SJ, Ahmadi K, Timms J, Katso R, Driscoll PC, Woscholski R, Parker PJ, Waterfield MD (2001) Synthesis and function of 3-phosphorylated inositol lipids. Annu Rev Biochem 70:535-602

Vicogne J, Vollenweider D, Smith JR, Huang P, Frohman MA, Pessin JE (2006) Asymmetric phospholipid distribution drives in vitro reconstituted SNARE-dependent membrane fusion. Proc Natl Acad Sci U S A 103:14761-14766

Vidali L, McKenna ST, Hepler PK (2001) Actin polymerization is essential for pollen tube growth. Mol Biol Cell 12:2534-2545

Vidugiriene J, Menon AK (1993) Early lipid intermediates in glycosyl-phosphatidylinositol anchor assembly are synthesized in the ER and located in the cytoplasmic leaflet of the ER membrane bilayer. J Cell Biol 121:987-996

Vidugiriene J, Menon AK (1994) The GPI anchor of cell-surface proteins is synthesized on the cytoplasmic face of the endoplasmic reticulum. J Cell Biol 127:333-341

Volpicelli-Daley L, De Camilli P (2007) Phosphoinositides' link to neurodegeneration. Nat Med 13:784-786

Walch-Solimena C, Novick P (1999) The yeast phosphatidylinositol4-OH kinase pik1 regulates secretion at the Golgi. Nat Cell Biol $1: 523-525$

Wasteneys GO, Galway ME (2003) Remodeling the cytoskeleton for growth and form: an overview with some new views. Annu Rev Plant Biol 54:691-722

Wasteneys GO, Yang Z (2004) New views on the plant cytoskeleton. Plant Physiol 136:3884-3891

Welters P, Takegawa K, Emr SD, Chrispeels MJ (1994) AtVSP34, a phosphatidylinositol 3-kinase of Arabidopsis thaliana, is an essential protein with homology to a calcium-dependent lipid binding domain. Proc Natl Acad Sci U S A 91:11398-11402

Wen TJ, Hochholdinger F, Sauer M, Bruce W, Schnable PS (2005) The roothairless 1 gene of maize encodes a homolog of sec3, which is involved in polar exocytosis. Plant Physiol 138:16371643

Westergren T, Ekblad L, Jergil B, Sommarin M (1999) Phosphatidylinositol 4-kinase associated with spinach plasma membranes. 
Isolation and characterization of two distinct forms. Plant Physiol 121:507-516

Whatmore J, Morgan CP, Cunningham E, Collison KS, Willison KR, Cockcroft S (1996) ADP-ribosylation factor 1-regulated phospholipase D activity is localized at the plasma membrane and intracellular organelles in HL60 cells. Biochem J 320(Pt 3):785794

Whitley P, Hinz S, Doughty J (2009) Arabidopsis FAB1/PIKfyve proteins are essential for development of viable pollen. Plant Physiol 151:1812-1822

Williams ME, Torabinejad J, Cohick E, Parker K, Drake EJ, Thompson JE, Hortter M, Dewald DB (2005) Mutations in the Arabidopsis phosphoinositide phosphatase gene SAC9 lead to overaccumulation of $\operatorname{PtdIns}(4,5) \mathrm{P} 2$ and constitutive expression of the stress-response pathway. Plant Physiol 138:686-700

Xue HW, Pical C, Brearley C, Elge S, Muller-Rober B (1999) A plant $126-\mathrm{kDa}$ phosphatidylinositol 4-kinase with a novel repeat structure. Cloning and functional expression in baculovirusinfected insect cells. J Biol Chem 274:5738-5745

Yamamoto M, Hilgemann DH, Feng S, Bito H, Ishihara H, Shibasaki Y, Yin HL (2001) Phosphatidylinositol 4, 5-bisphosphate induces actin stress-fiber formation and inhibits membrane ruffling in CV1 cells. J Cell Biol 152:867-876

Yoshida S, Ohya Y, Goebl M, Nakano A, Anraku Y (1994) A novel gene, STT4, encodes a phosphatidylinositol 4-kinase in the PKC1 protein kinase pathway of Saccharomyces cerevisiae. J Biol Chem 269:1166-1172
Zhang H, Craciun LC, Mirshahi T, Rohacs T, Lopes CM, Jin T, Logothetis DE (2003) PIP(2) activates KCNQ channels, and its hydrolysis underlies receptor-mediated inhibition of $\mathrm{M}$ currents. Neuron 37:963-975

Zhong R, Ye ZH (2004) Molecular and biochemical characterization of three WD-repeat-domain-containing inositol polyphosphate 5phosphatases in Arabidopsis thaliana. Plant Cell Physiol 45:1720-1728

Zhong R, Burk DH, Morrison WH 3rd, Ye ZH (2004) FRAGILE FIBER3, an Arabidopsis gene encoding a type II inositol polyphosphate 5-phosphatase, is required for secondary wall synthesis and actin organization in fiber cells. Plant Cell $16: 3242-3259$

Zhong R, Burk DH, Nairn CJ, Wood-Jones A, Morrison WH 3rd, Ye ZH (2005) Mutation of SAC1, an Arabidopsis SAC domain phosphoinositide phosphatase, causes alterations in cell morphogenesis, cell wall synthesis, and actin organization. Plant Cell 17:1449-1466

Zonia L, Munnik T (2009) Uncovering hidden treasures in pollen tube growth mechanics. Trends Plant Sci 14:318-327

Zonia L, Cordeiro S, Tupy J, Feijo JA (2002) Oscillatory chloride efflux at the pollen tube apex has a role in growth and cell volume regulation and is targeted by inositol 3, 4, 5, 6tetrakisphosphate. Plant Cell 14:2233-2249

Zonia L, Muller M, Munnik T (2006) Hydrodynamics and cell volume oscillations in the pollen tube apical region are integral components of the biomechanics of Nicotiana tabacum pollen tube growth. Cell Biochem Biophys 46:209-232 